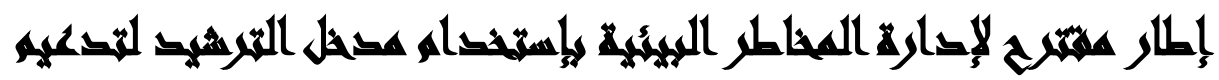

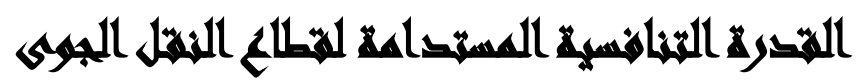

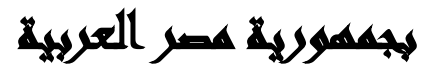

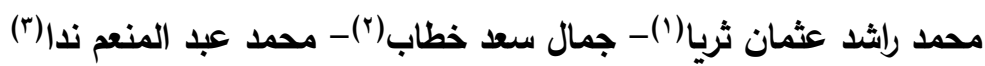

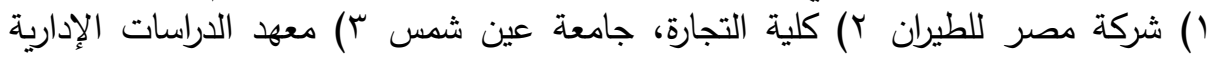 \\ والتعاونية
}

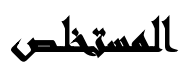

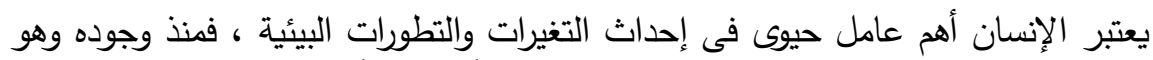

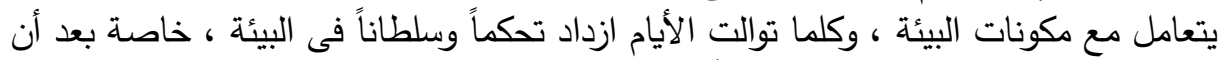

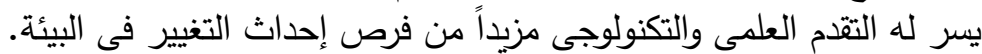

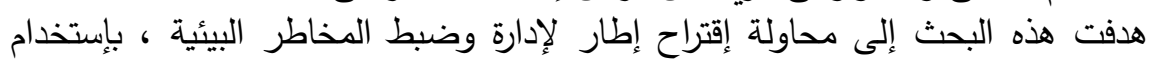

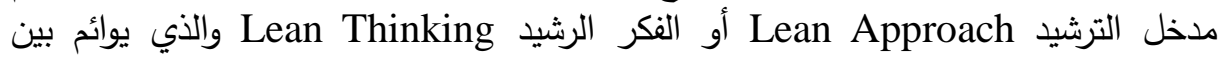

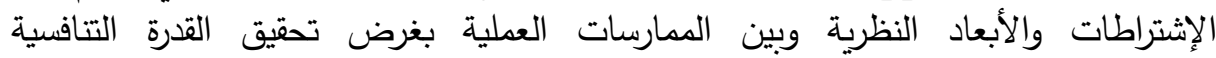

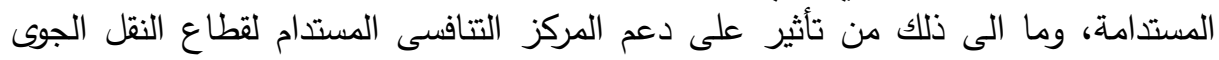

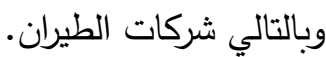

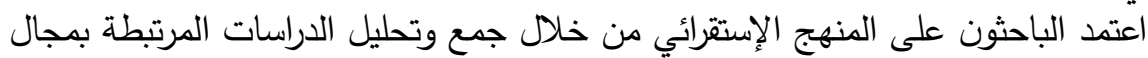

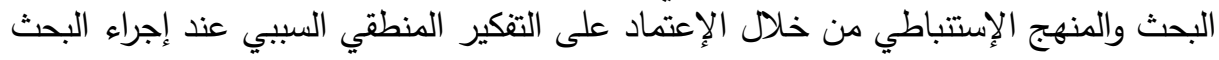

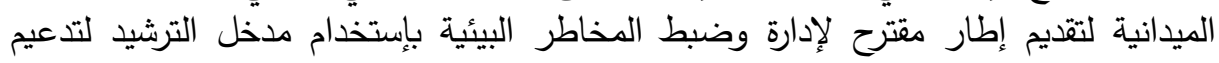

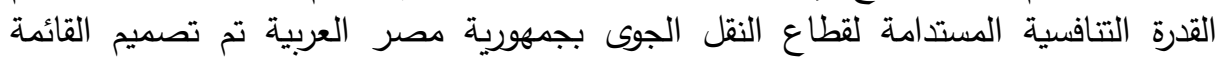

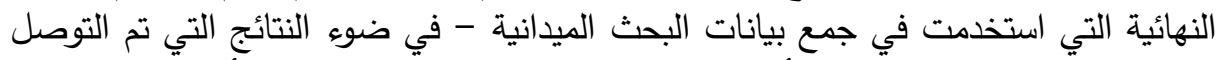

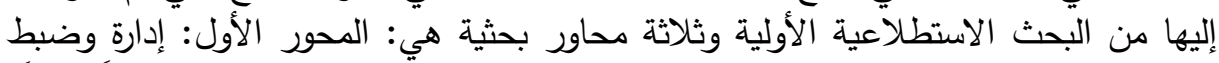

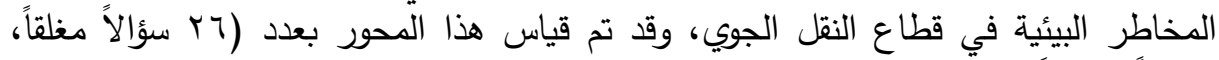

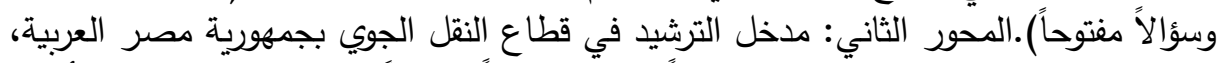

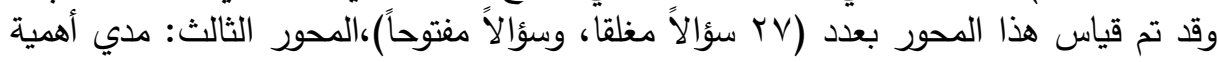

$$
\begin{aligned}
& \text { r. . . المجلد التاسع والأربعون، العدد التاسع، الجزء السابع، سبتمبر }
\end{aligned}
$$

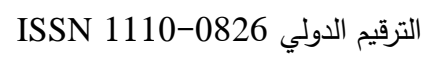




$$
\begin{aligned}
& \text { مجلة العلوم البيئية } \\
& \text { معهد الدراسات والبحوث البيئية - جامعة عين شمس بـ مع } \\
& \text { محمد راشد عثمان وآخرون }
\end{aligned}
$$

القدرة التنافسية المستدامة فى قطاع النقل الجوي، وقد تم قياس هذا المحور بعدد (·r سؤالاً

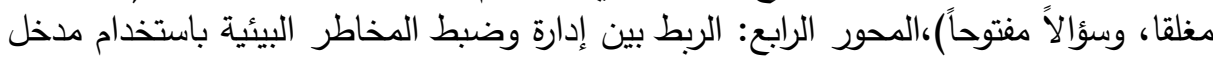

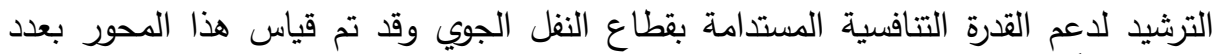

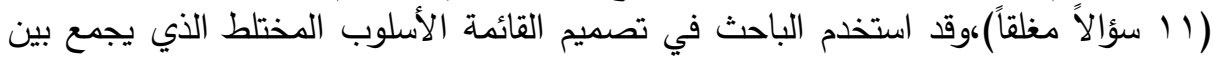

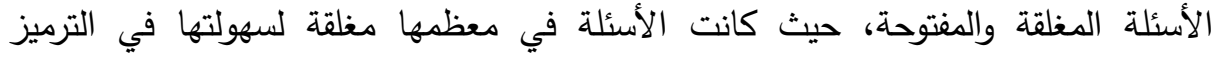

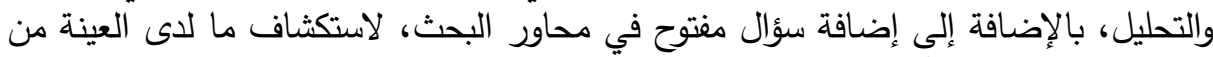

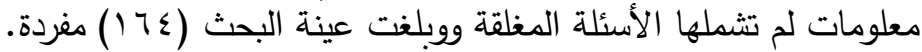

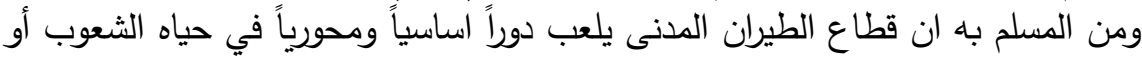

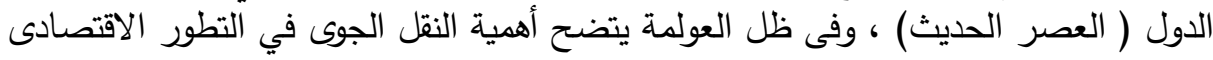

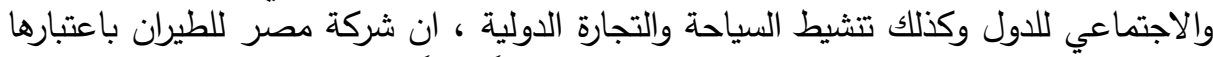

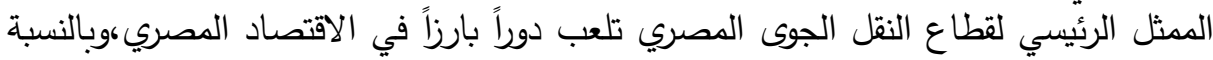

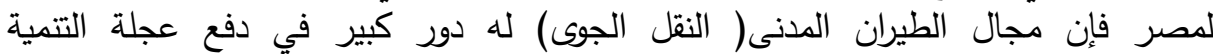

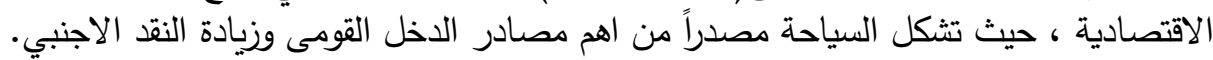

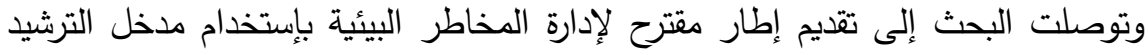

لتدعيم القدرة التتافسية المستدامة لقطاع النقل الجوى بجمهورية مصر الإن العربية. وأوصت البحث بضرورة الإهتمام بمدخل الترشيد والاستفادة من ألياته في ادارة المخاطر

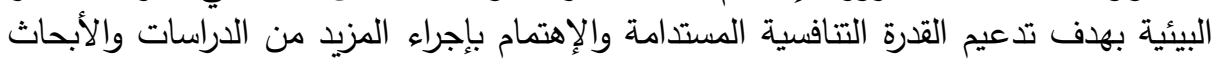

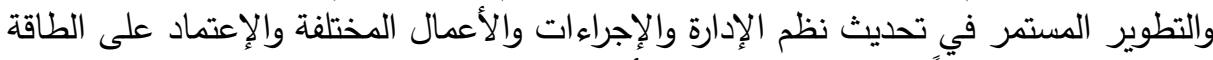

الجديدة والمتجددة بدلًا من استخدام الطاقة الأحفورية.

الكلمات الدالة: ادارة المخاطر البيئية Environmental Risk Management،

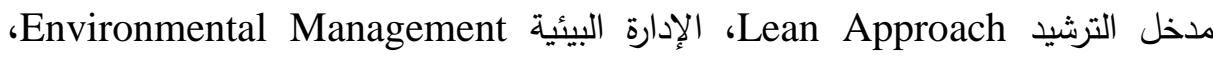
الميزة التتافسية Competitive Advantage، الإستدامة Sustainability، النقل الجوي

- Air Transport

\section{المهian}

أدت الثورة الصناعية والتقدم التكنولوجى الحديث الي آثار سلبية على البيئة ، فإنطلاق

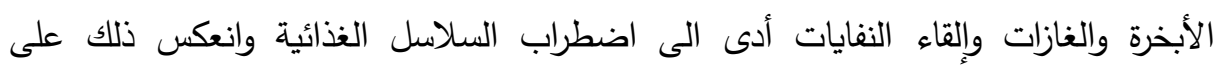

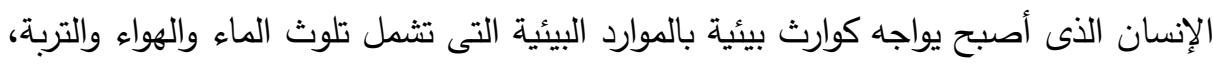

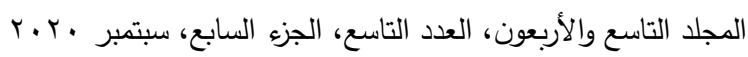

$$
\begin{aligned}
& \text { الترقيم الدولي 0826- ISSN 1110 }
\end{aligned}
$$


مما أدى الى اتجاة الأفراد والمنظمات والدول المختلفة نحو وضع معايير بيئية والتزامات

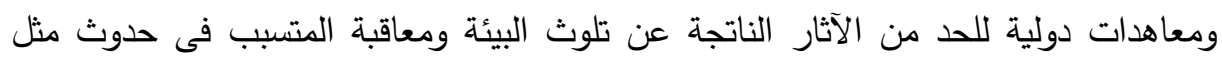
هذه الكوارث البيئية، ومن هذه المؤتمرات مؤتمر الأمم المتحدة للبيئة والتنمية فى استكهولم

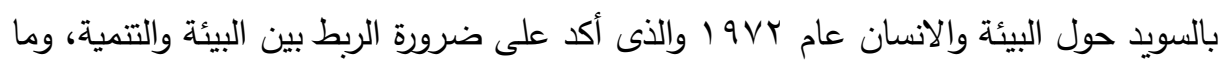

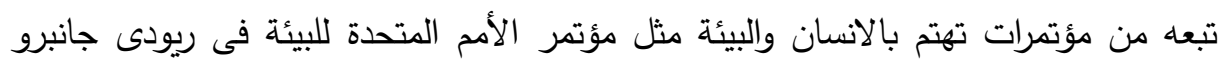

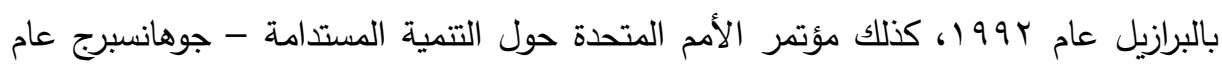

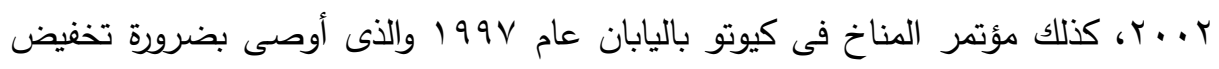

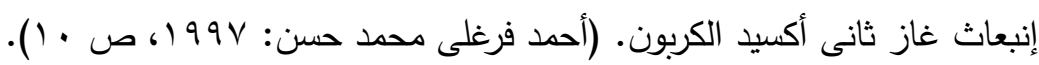

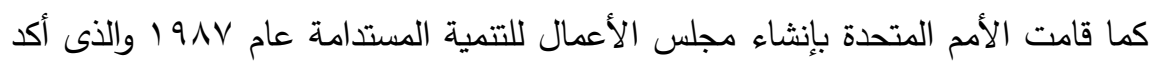

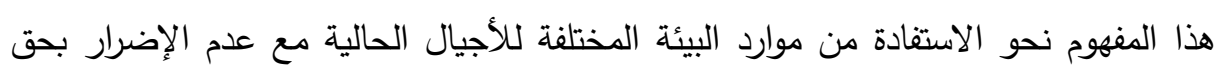
الأجيال القادمة فى الحصول على هذة الموارد والقضاء على أسباب التلوث المختلفة. ( https:// ar.m.wikipedia.org- https//: www.un.org.) ويعتبر مدخل الترشيد Lean Approach ومنهجية الاستدامة Sustainability والتى أثتت فعاليتها في تحقيق نتائج إيجابية فى مختلف المنظمات العالمية من أهم المناهج العلمية الحديثة والتى أثبتت نجاحات متعددة فى الادارة الاستراتيجية للمخاطر البيئية وتحقيق ميزة تنافسية ولا تزال محل اهتمام العديد من الثركات العالمية. ويعد التلوث الضوضائي (السمعي) الناتج عن تثغيل محركات الطائرات أحداهم مسببات التلوث في قطاع النقل الجوي، والذي يؤثر علي العنصر البشري بالسلب وينتج عنه مشاكل صحية متتوعة للعاملين داخل الحقل الجوي منها إنخفاض مستوي السمع وزيادة نسبة العصبية وعدم التركيز ، مما يؤدي إلي إنخفاض مستوي الآراء لهؤلاء العاملين.

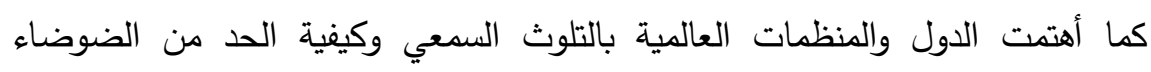

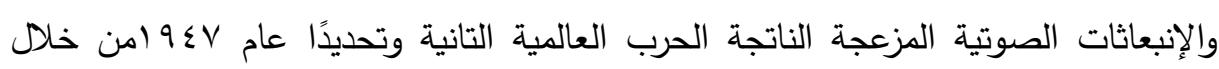

$$
\begin{aligned}
& \text { r. . . المجلد التاسع والأربعون، العدد التاسع، الجزء السابع، سبتمبر }
\end{aligned}
$$

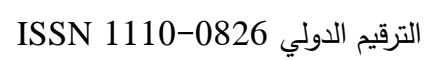


القوانين والمؤتمرات أهمها من المحركات والآلات ووسائل النقل المختلفة منذ إنعقاد المؤتمر

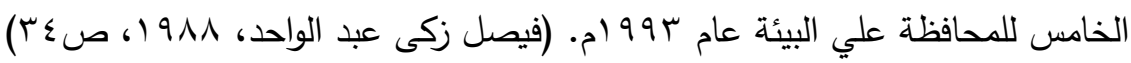
قامت منظمات الطيران الدني الدولية يوضع معايير أساسية للحد من إرتفاع نسبة

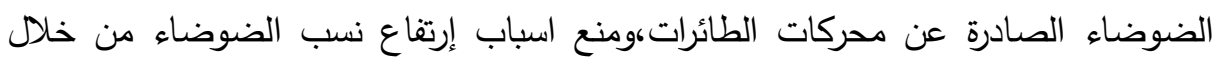

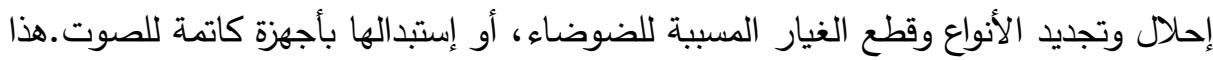

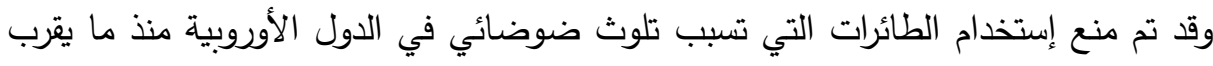

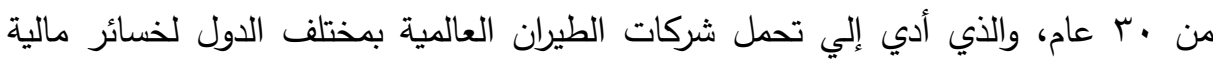

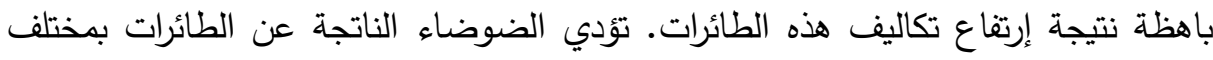
أنواعها (البسيطة- الثديدة- الصاغبة) إلي حدوث تلوث سمعي بالمناطق الغريبة من مواقع

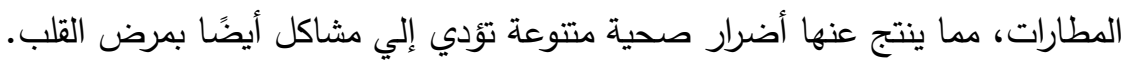

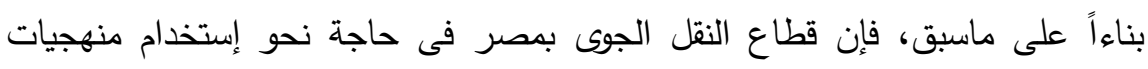

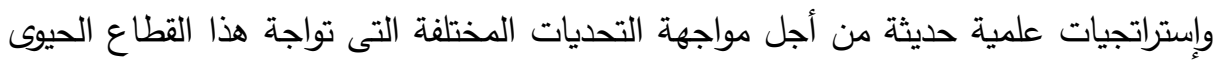
والإستراتيجى من أهمها مشكلة ارتفاع معدلات التلوث البيئى وما يترتب عليه من مخاطر بيئية تؤثر بشكل سلبى على مستقبل قطاع الطيران المدني.

\section{And ILan}

إن التحليل الإحتمالي للخطر أو يسي التحليل الكمي للخطر يطبق حالياً في الكثير من

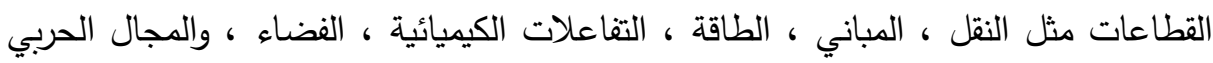
وحتي في تخطيط وتمويل المشروعات وهي تستخدم في الإطار التنظيمي بواسطة الجهات

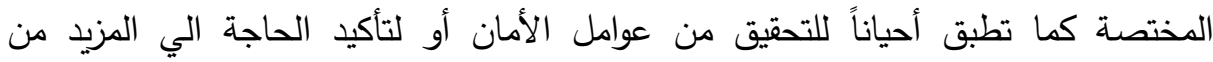

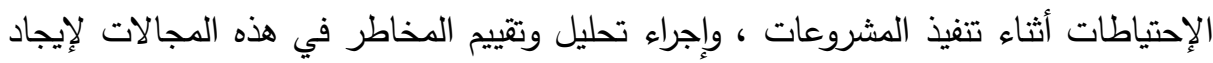

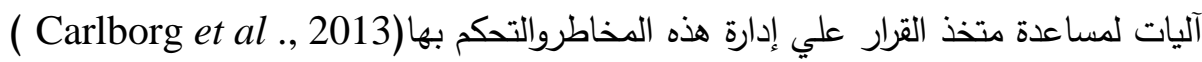

$$
\begin{aligned}
& \text { r. r. • المجلد التاسع والأربعون، العدد التاسع، الجزء السابع، سبتمبر } \\
& \text { الترقيم الدولي 0826-110 110 الارعون، }
\end{aligned}
$$


كما أن التقييم البيئي لمخاطر بيئة العمل يعني الخطة المتكاملة لعملية تقييم مستوي المخاطر في بيئة العمل وعلي ضوء ذلك يتم اتخاذ القرار المناسب.(Anna Misiura , 2015 ) إن وزراة الطيران المدني المصرية تدرك أهمية الحفاظ علي حقوق الأجيال القادمة في

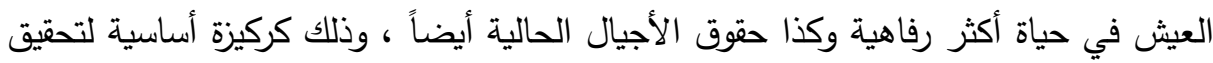
التتمية المستدامة (التتمية من أجل الإنسان)، والتتمية المستدامة في الواقع هي “فئهوم شامل

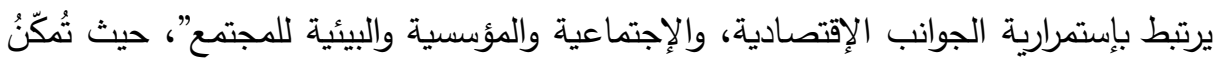

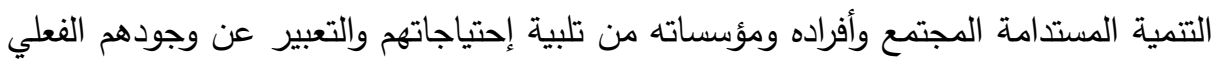

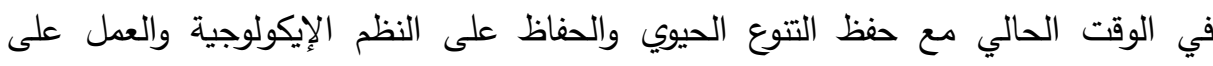

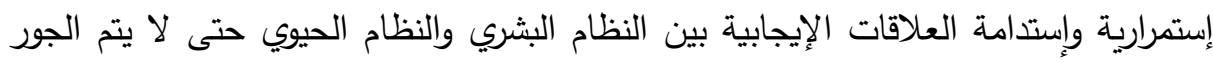
على حقوق الأجيال القادمة في العيش بحياة كريمة ويعتبر هذا من أهم إستراتيجيات الطيران

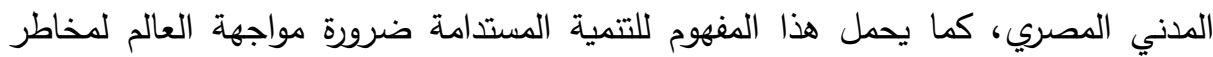

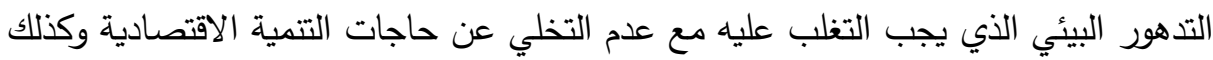
المساواة والعدل الإجتماعي. تتمثل المشكلة الأساسية لهذا البحث فى قلة المناهج والأدوات العلمية التى تستخدم فى الحد من المخاطر البيئية وعدم تطبيق السياسات البيئية الملائمة التى تواجة قطاع النقل الجوى فى مصر، وكذلك محاولة وضع إطار مقترح عام لمنهجية بيئية وذلك للحد من لن

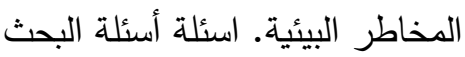
- كيف يمكن تحقيق الاستدامة بقطاع النقل الجوى من خلال إدارة المخاطر البيئية؟

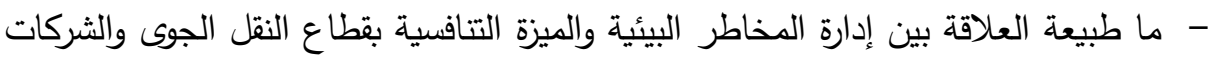
العاملة به؟

- - كيف يمكن إستخدام مدخل الترشيد في مجال النقل الجوى وبالتالى شركات الطيران؟

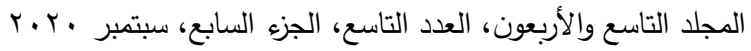

$$
\begin{aligned}
& \text { الترقيم الدولي 0826-0 1110 }
\end{aligned}
$$


- - ما أهم الاليات والمهمات التى يمكن استخدامها لتدعيم القدرة التنافسية المستدامة لشركات الطيران؟ - - ما المنافع والمزايا المترتبة على إدارة المخاطر البيئية لشركات الطيران؟ - يف يساهم مدخل الترشيد في الحفاظ على البيئة؟ - ما مدى وجود علاقة بين مدخل الترشيد والميزة التتافسية لشركات الطيران؟

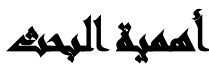

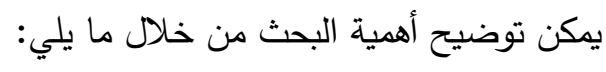
الأهمية العلمية: تأتى أهمية هذة البحث فى تتاوله لإحدى المشكلات الهامة والحديثة التى

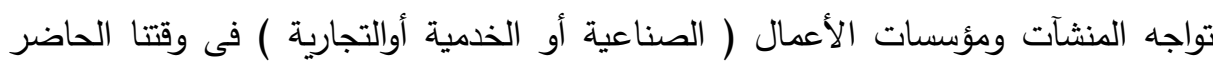
وهى كيفية التوفيق بين تخفيض معدلات التلوث البيئى وتحقيق مستوى متميز من الجودة

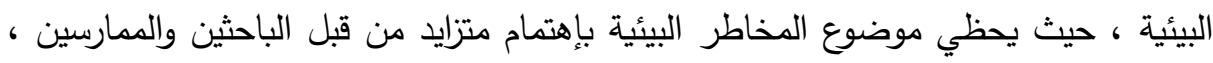

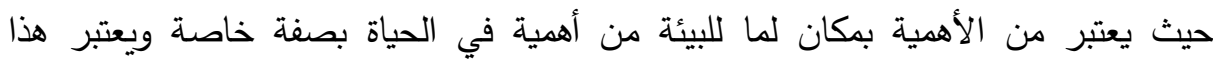

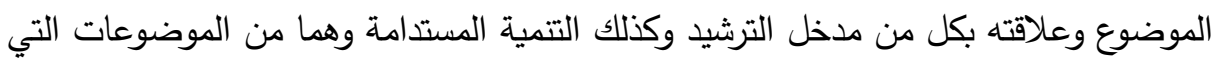

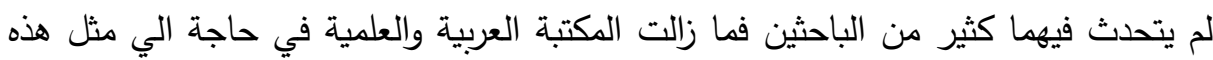
الدراسات.

الأهمية العملية: ترجع الأهمية العملية لهذه البحث الي أنه في ظل التحديات التي يمر بها المجتمع فان هذه البحث تتحدث عن المخاطر البيئية في قطاع النقل الجوي وبالتالي تكون النهائه النظرة لهذا الموضوع من الناحية العملية هامة جدا حيث أن تطوير أداء النقل الجوي والحفاظ

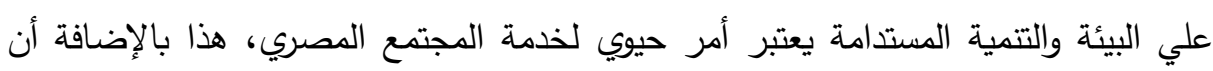

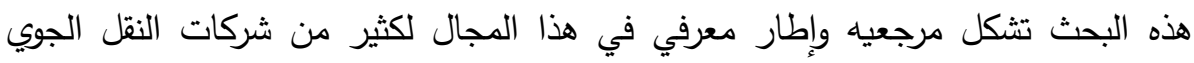
العاملة في مصر ، ووضع الموضوع أمام القيادات العليا للشركة متخذة القرار بطريقة علمية.

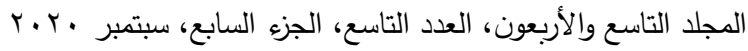

$$
\begin{aligned}
& \text { الترقيم الدولي 0826- ISSN 1110 }
\end{aligned}
$$




\section{أمساهنم الهمبه}

تهدف البحث بشكل أساسى إلى محاولة اقتراح إطار للتكامل بين إدارة الدخاطر البيئية، بإستخدام مدخل الترشيد (LA) يوائم بين الإشتراطات والأبعاد النظرية وبين الممارسات العملية بغرض تحقيق التتمية المستدامة، وما إلى ذلك من تأثير على دعم المركز التتافسى لحركة

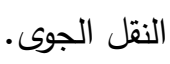

كما توجد أهداف فرعية للدراسة منها:

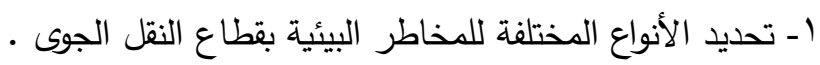

r- تحديد ماهية إدارة المخاطر البيئية . r- توضيح أهمية مدخل الترشيد ومدى تأثيره على شركة مصر للطيران.

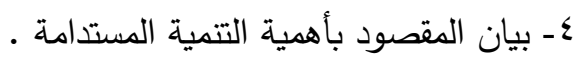

0- توضيح العلاقة بين المخاطر البيئية وأثر ذلك علي تحقيق التتمية المستدامة .

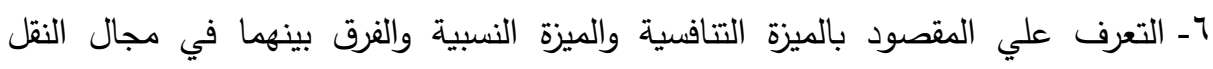
الجوي.

V- وضع إطار نظري يربط بين مدخل الترشيد والقدرة التتافسية المستدامة. ^- التعرف على أثر إدارة المخاطر البيئة في بناء الميزة التنافسية لشركات الطيران.

$$
\begin{aligned}
& \text { r. r. • المجلد التاسع والأربعون، العدد التاسع، الجزء السابع، سبتمبر }
\end{aligned}
$$

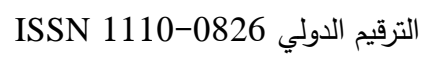




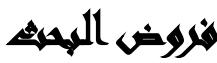

يتمثل فرض البحث الرئيسى فى وجود علاقة ارتباط جوهرية بين المعلومات التى يوفرها الإطار المقترح الذى يهدف إلى إدارة وضبط المخاطر البيئية بإستخدام مدخل الترشيد (LA)

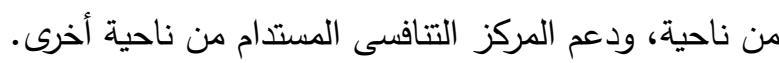
وتتمثل متغيرات فرض البحث الرئيسى فى : البهى - المتغير المستقل : إدارة وضبط المخاطر البيئية. - المتغير التابع : دعم المركز التتافسى المستدام. - - المتغير الوسيط : مدخل التزشيد.

ويتم تقسيم الفرض الرئيسى الى الفروض الفرعية التالية: 1- توجد علاقة ذات دلالة إحصائية بين تطبيق إدارة المخاطر البيئية وبين تحقيق ميزة البئي تنافسية مستدامة فى قطاع النقل الجوى فى مصر . r- توجد علاقة إرتباط جوهرية بين إستخدام مدخل الترشيد وتدعيم القدرة التتافسية المستدامة فى قطاع النقل الجوى فى مصر .

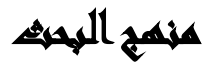

تم إتباع المنهج الإستقرائي، فهو عملية إستدلال تصاعدي، يرتقي فيه الباحث من

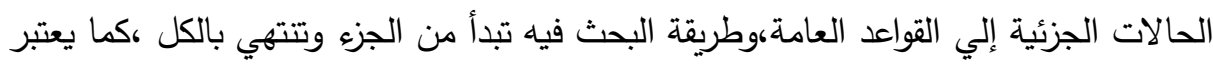
التتبؤ من أهم المعالم التي تتميز هذا المنهج، والبحث في المنهج الإستقرائي تمر بثلاثة مراحل

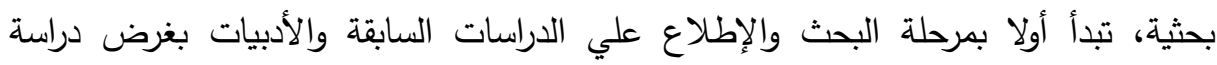

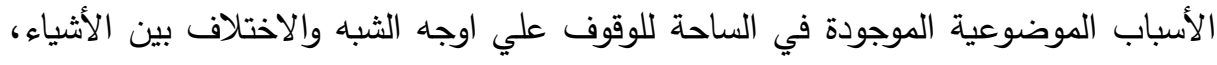

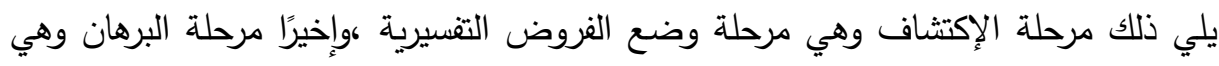
مرحلة التحقق من الفروض من خلال البحث الميدانية.

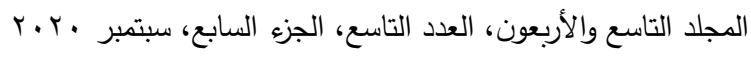

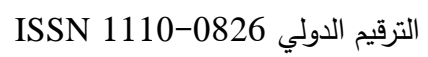




$$
\begin{aligned}
& \text { مجلة العلوم البيئية } \\
& \text { معهد الدراسات والبحوث البيئية - جامعة عين شمس بـ مع } \\
& \text { محمد راشد عثمان وآخرون }
\end{aligned}
$$

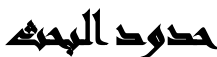

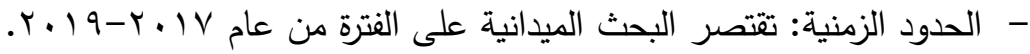

- الحدود المكانية: تشمل البحث شركة مصر للطيران ( ممثلخً لقطاع النقل الجوي بجمهورية

$$
\text { مصر العربية ). }
$$

- الحدود الموضوعية: تقتصر البحث علي وضع إطار مقترح لإدارة المخاطر البيئية بإستخدام مدخل الترشيد لتدعيم القدرة التتافسية المستدامة لقطاع النقل الجوي بجمهورية

$$
\text { مصر العربية . مصن. }
$$

\section{السراسايت السايرية}

دراسة Sean Murphy, 2011 بعنوان:

The Status of Lean Implementation within South African Aircraft Maintenance Organization:

هدفت هذه البحث إلى تحديد مستوى تتفيذ منهجية الإنتاج الخالي من الفاقد داخل مرافق

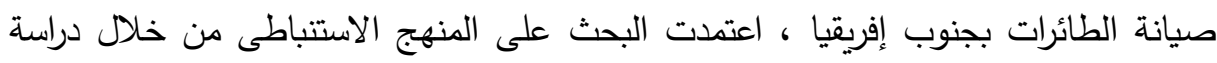
واستتباط الأبحاث العلمية المتعلقة بموضوع البحث.

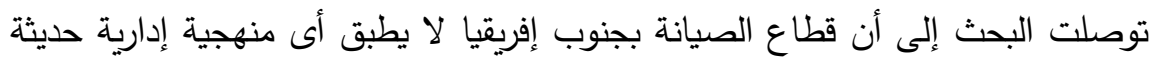

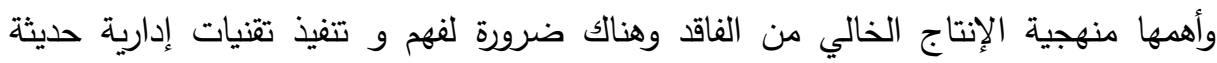
متمثلة فى منهجية الإنتاج الخالي من الفاقد ، والستة سيجما لضمان مستقبل قطاع صيانة ونسان

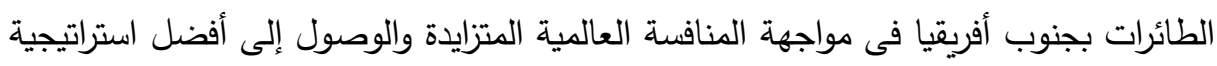
لخفض تكاليف صيانة الطائرات. دراسة Palanivel Subramaniyam, 2011 An Innovative lean six sigma Approach for Engineering Design:

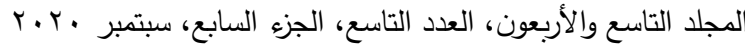

$$
\begin{aligned}
& \text { الترقيم الدولي 0826-0 التونون }
\end{aligned}
$$


هدفت هذه البحث إلى تحسين أداء العاملين من خلال تحسين التصميم وتقليل وقت التصميم وتقليل وزن المواد الخام ، الحد من التكاليف الزائدة وذلك بإستخدام منهجية الستة سيجما ومنهجية

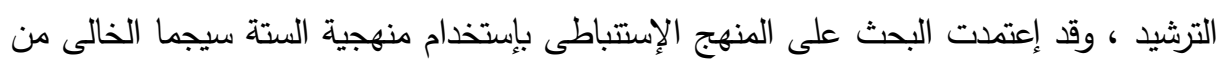
الفاقد من أجل تحقيق أفضل أداء للتصميم الهندسى للعمليات.

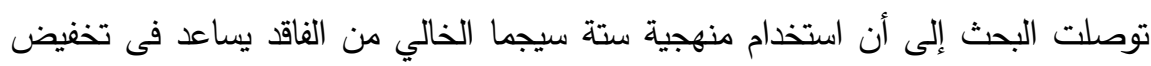

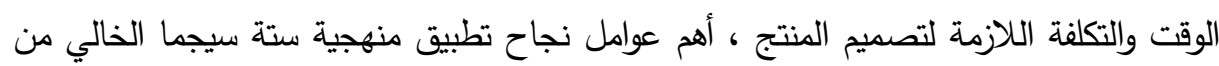
الفاقد هو الإلتزام والتتسيق والتعاون بين المشاركين فى تفعيل هذة المنهجية.

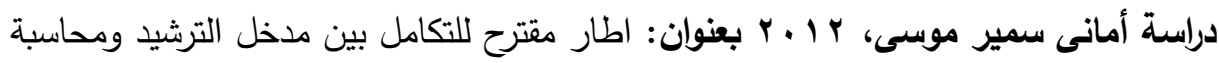
استهلاك الموارد بغرض دعم المركز التتافسى للوحدات الاقتصادية - دراسة تطبيقية

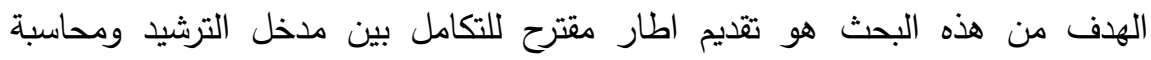
استهلاك الموارد بغرض ترشيد التكلفة ودعم المركز التتافسي ، اعتمدت البحث على المنهج

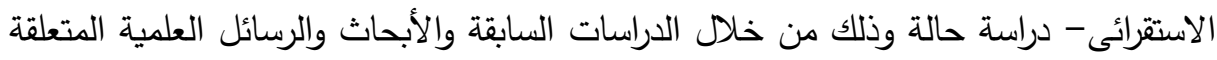
بموضوع البحث وشملت دراسة الحالة احدى الوحدات الإقتصادية فى مصر .

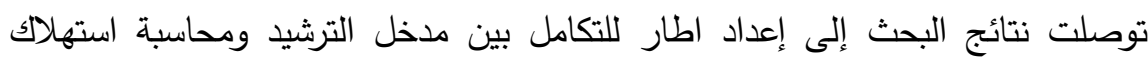
الموارد يساعد المنظمات الى الحد من الفاقد والهدر فى الموارد مما يؤدى الى الاستغلال الأمثل للموارد ورفع كفاءة أداء العاملين وملاحقة التطورات التكنولوجية ودعم القدرة التتافسية. دراسة Ana- Maria, 2016 بعنوان:

The Economic Dimension of Environmental Risk management in knowledge- Based society:

هدفت هذه البحث إلى تحديد وتحليل وتقييم المخاطر البيئية وذلك بإستخدام المنهج الإستقرائى الإستتباطى ، توصلت البحث إلى أن هنالك عدد من المصادر المتتوعة للمخاطر

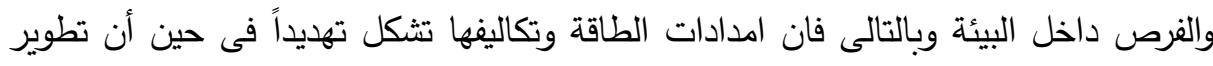
مصادر الطاقة المتجددة يمثل فرص يجب تحديد مسئولية وسلطة الاشخاص المشتركين فى ليى 568

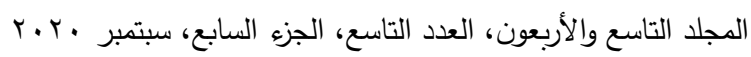

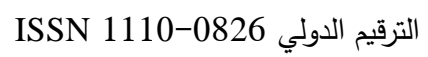




$$
\begin{aligned}
& \text { مجلة العلوم البيئية } \\
& \text { معهد الدراسات والبحوث البيئية - جامعة عين شمس بـ مع } \\
& \text { محمد راشد عثمان وآخرون }
\end{aligned}
$$

ادارة المخاطر والعلاقة بينهم من خلال وثائق واضحة، لاسيما الأشخاص الذين لايهم مسئوليات إدارة المخاطر البيئية. دراسة Tatyana chernova, 2014 Risk management Application for the IATA E-Freight initiative in air cargo industry

هدفت هذه البحث الاستفادة من تطبيق ادارة المخاطر بمنظمة الإياتا لخفض معدلات المخاطر

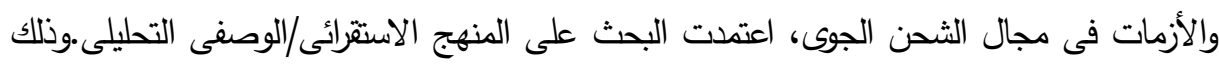

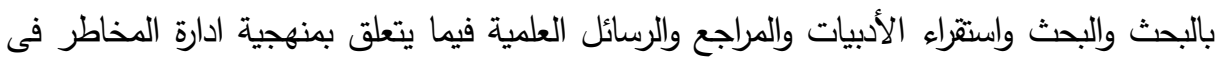

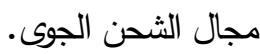

توصلت البحث الى أن مسئولى التخليص الجمركى ووكلاء الثحن والمناولة الأرضية الأكثر خطورة فيما يتعلق بأعمال الثحن الآكترونى. دراسة Anna Misiura, 2015

Enterprise Risk management in the airline industry - risk management structures and practices

هدفت هذه البحث الى تقديم اطار عام ودراسة تطبيقية لإدارة المخاطر فى مجال خدمات صناعة الطيران ، اعتمدت البحث على المنهج الاستقرائى/التجربيى ونلك باستخدام . . اعينة داخل •

توصلت البحث الى تقيم اطارا عاما لاستخدام مشروع ادارة المخاطر ERM فى مجال صناعة الطيران- وأكدت أن اتباع كلا من التعليمات الموثقة لمنظمات الطيران العالمية والالتزام بالتحديث التقنى والتكنولوجى وققا للمعايير العالمية هما أساس السيطرة والتحكم على مخاطر صناعة الطيران.

$$
\begin{aligned}
& \text { r. r. • المجلد التاسع والأربعون، العدد التاسع، الجزء السابع، سبتمبر } \\
& \text { الترقيم الدولي 0826-0 الاربعني }
\end{aligned}
$$


تقييم الاراسات السابقة والنتائج التح تم التوصل إليها:

تعتبر الدراسات السابقة أساس ودعم لهذا البحث، وذلك بالاستفادة من النتائج الإيجابية والتي تم الحصول عليها من هذه الدراسات وفي نفس الوقت تلافي مواطن القصور والاختلافات التي ترتبط بموضوع هذا البحث.

البحث الحالي التي يقوم به الباحث تتفق مع الدراسات السابقة فيما يلي:

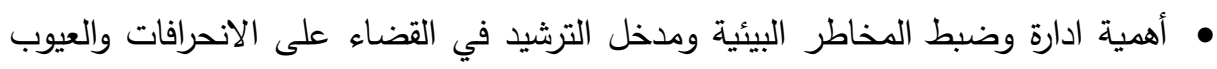

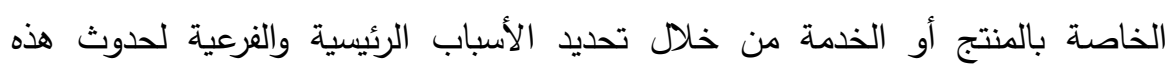
الانحرافات ومن ثم معالجة الأخطاء التي تسببت في حدوثها. •ادارة المخاطر البيئية ومدخل الترشيد تتضمن أدوات علمية وإحصائية حديثة ومتطورة يمكن من خلالها الحصول على بيانات ومعلومات دقيقة وتفصيلية عن ديناميكية الأعمال المختلفة والتي تمكن المنظمة من الحصول على أهم أسباب الأخطاء والمشاكل المرتبطة بالمنتج أو الخدمة. • نجاح تطبيق مدخل الترشيد يعتمد على مدى التزام الإدارة العليا واهتمامها بهذه المنهجية، توافر الموارد البشرية المؤهلة والمدربة وذوي الخبرة.

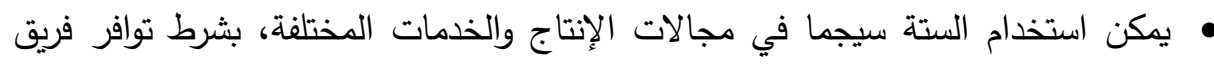
عمل مؤهل علميًا وعمليًا في استخدام الستة سيجما.

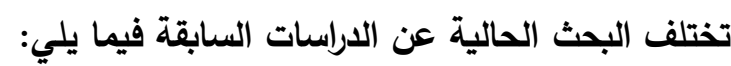
• اهتمت الدراسات السابقة بكيفية القضاء على أسباب حدوث المخاطر البيئية والآثار السلبية المترتبة على هذه المخاطر، ولم تحظى بالإهتمام الكافى فيما يخص كيفية الادارة

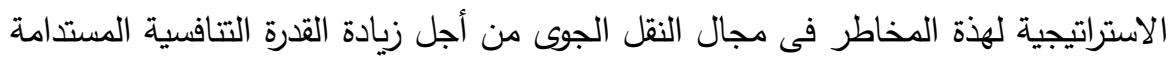
لهذا القطاع الحيوى ، بينما البحث الحالية تتاولت كيفية الادارة للمخاطر البيئية بشكل ملتهل

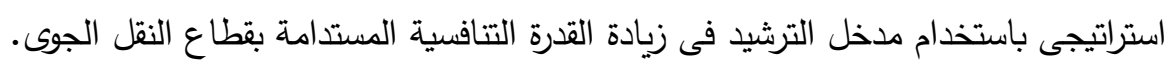
570

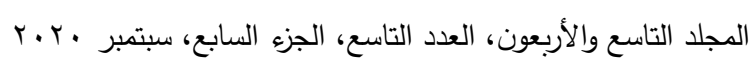

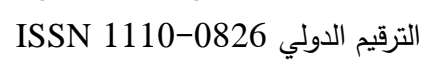


• أجمعت الدراسات السابقة على أهية كلا من مدخل الترشيد وادارة الدخاطر البيئية ودورهما فى تحقيق تتمية استراتيجية للمنظمات العالمية والحد من الفاقد والتالف وتطوير الأداء بما يتواكب مع الاهتمام العالمى للبيئة والتتمية المستدامة وتحقيق أقصى استفادة

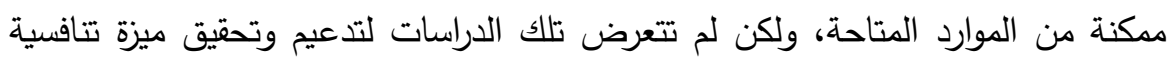

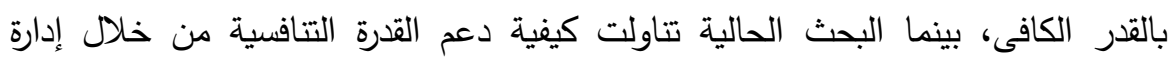

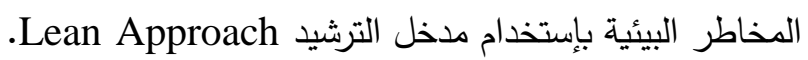
• اهتمت معظم الدراسات السابقة بالأدوات العلمية والفنية لمنهجية الترشيد وادارة المخاطر

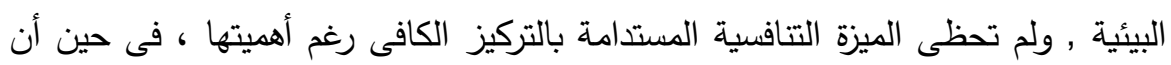

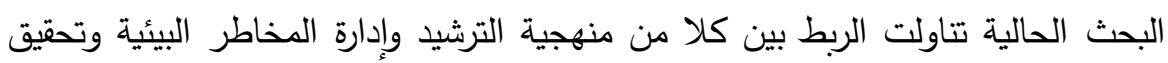
ميزة تتافسية فى ظل منهجية الاستدامة.

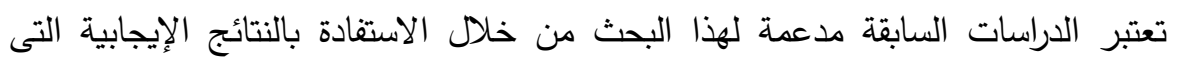

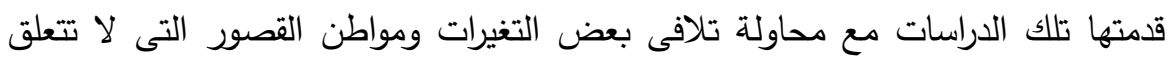

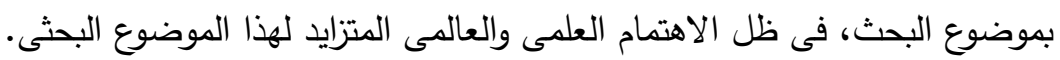

\section{الإسار اللنظليهي}

تعريف المخاطر البيئية: فيما يلي نستعرض بعض التعريفات المختلفة للمخاطر التي يمكن

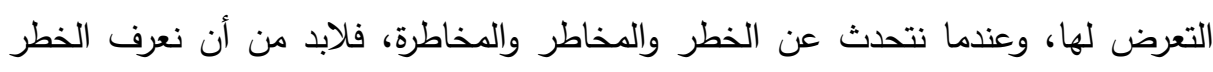

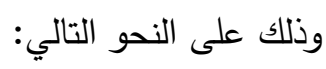

عرف "دريفنك" الخطر (Drivnsek (L): 1990, p.19): "على أنه شئ ممكن أن

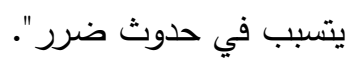

وعرفت الأدبيات والبحوث الأجنبية والعربية المصطلح بأنه "التهديدات الكاملة للإنسان وتأثيراتها على المجتمع والبيئة"، وهذا التعريف يثير إلى إمكانية أو احتمالية حدوث تأثيرات

$$
\begin{aligned}
& \text { r. . . المجلد التاسع والأربعون، العدد التاسع، الجزء السابع، سبتمبر }
\end{aligned}
$$

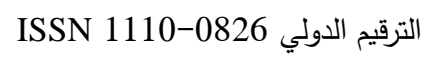


جانبية طفيفة أو حادة نتيجة لوقوع ضرر أو خطر ما ، ويؤكد أيضاً على أن هذه الأضرار

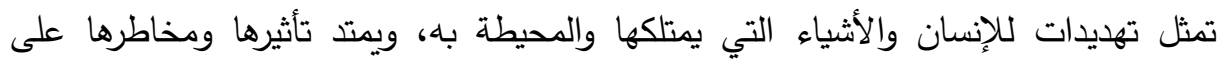
المجتمع والبيئة، وهي إلى حد كبير مرتبطة بالمدركات الخاصة بالأفراد وبخبراتهم، وهي أيضاً تتتوع طبقاً للتوع الثقافي والجغرافي ، وطبقاً للنوع والجنس، وكذلك الحالة الاقتصادية

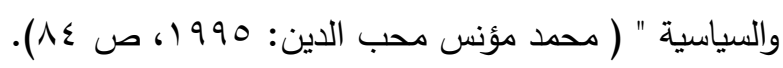

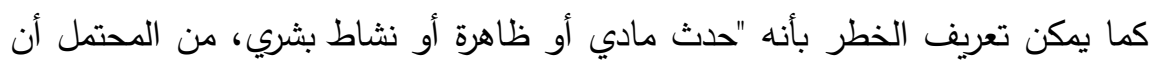

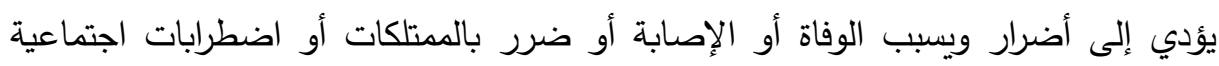

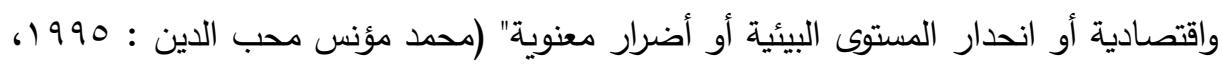
.) ص ص

قد تتضمن الأخطار ظروف كامنة، ربما تمثل تهديدات مستتبلية، يمكن أن تتشأ من أصول مختلفة (طبيعية جيولوجية ، مائية - طقسية ، وبيولوجية) أو تثار بفعل العمليات

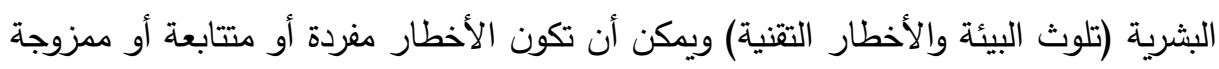
في أصلها أو أثرها ، وتحدد خصائص كل خطر بموقعه وشدته ومعدل تكراره واحتمال.

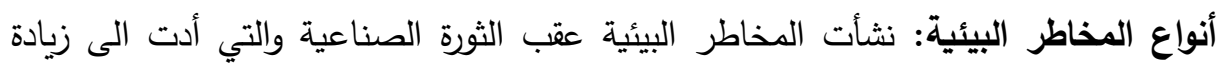
نسبة التلوث في المكونات الطبيعية للبيئة سواء كان لك بفعل الانسان أم نتيجة العوامل

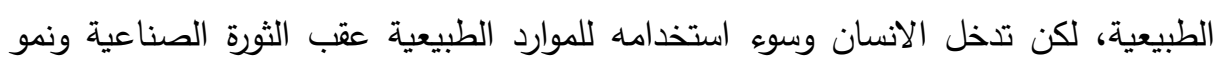
التكنولوجيا والتقنيات الصناعية الحديثة كان له تأثير كبير على زيادة نسبة التلوث البيئي

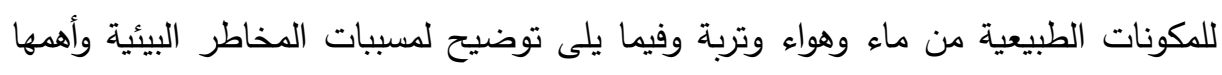

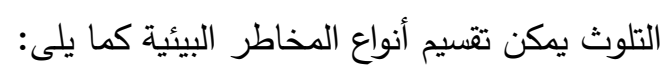
أنواع المخاطر البيئية من منظور صناعة النقل الجوى: نشأت المخاطر البيئية عقب الثورة

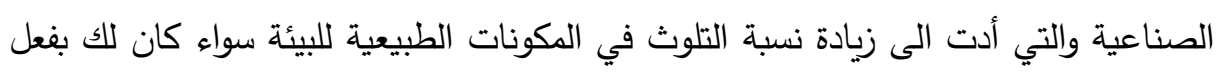

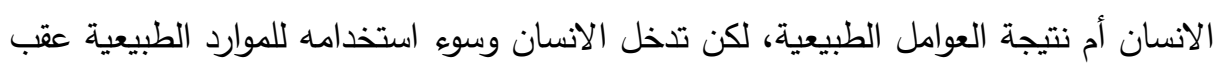

$$
\begin{aligned}
& \text { r. . . المجلد التاسع والأربعون، العدد التاسع، الجزء السابع، سبتمبر }
\end{aligned}
$$

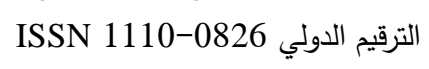


الثورة الصناعية ونمو التكنولوجيا والتقنيات الصناعية الحديثة كان له تأثير كبير على زيادة نسبة التلوث البيئي للمكونات الطبيعية من ماء وهواء وتربة وفيما يلى توضيح لمسببات المخاطر البيئية وأهمها التلوث. يمكن تقسيم أنواع المخاطر البيئية من منظور صناعة الفئل النقل الجوى الي: 1-التلوث السمعي(الضوضائي) الصادرة عن الطائرات ومتطلبات تثغيلها: (عبد اللطيف

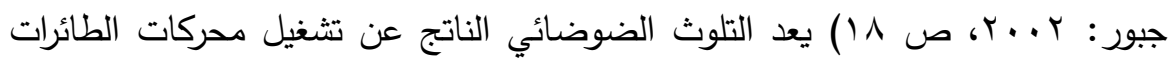
أحداهم مسببات التلوث في قطاع النقل الجوي، والذي يؤثر علي العنصر البشري بالسلب وينتج عنه مشاكل صحية متتوعة للعاملين داخل الحقل الجوي منها إنخفاض مستوي السمع وزيادة نسبة العصبية وعدم التركيز ،مما يؤدي إلي إنخفاض مستوي الآراء لهؤلاء العاملين.

كما أهتمت الدول والمنظمات العالمية بالتلوث السمعي وكيفية الحد من الضوضاء

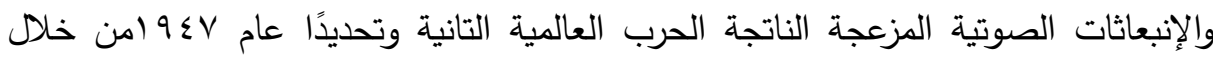
القوانين والمؤتمرات أهمها من المحركات والآلات ووسائل النقل المختلفة منذ إنعقاد المؤتمر

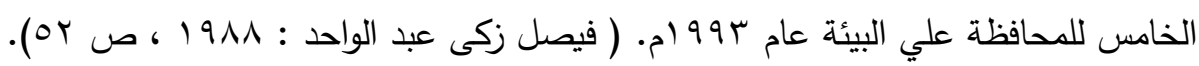
قامت منظمات الطيران المدني الدولية يوضع معايير أساسية للحد من إرتفاع نسبة إماحسة الضوضاء الصادرة عن محركات الطائراتهومنع اسباب إرتفاع نسب الضوضاء من خلال

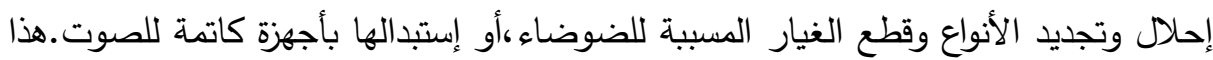

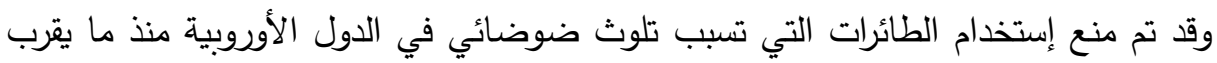
من • r عام، والذي أدي إلي تحمل شركات الطيران العالمية بمختلف الدول لخسائر مالية

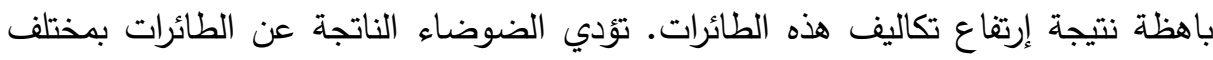
أنواعها (البسيطة- الثديدة- الصاغبة) إلي حدوث تلوث سمعي بالمناطق الغريبة من مواقع

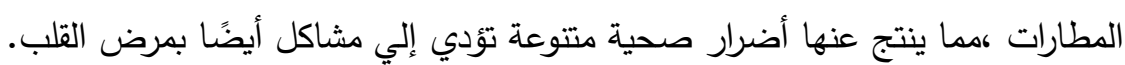

$$
\begin{aligned}
& \text { r. . . المجلد التاسع والأربعون، العدد التاسع، الجزء السابع، سبتمبر }
\end{aligned}
$$

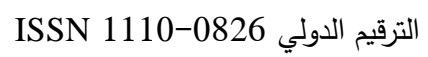


تختلف نسب تحديد الضوضاء المسموح بها طبقًا لعدة معايير أهمها: (اميرة السيد احمد امين:

(99-9V ص ص. T.) • • ن مع الطائرة.

• المسافات بين نقاط القياس المحددة لمختلف مسارات الطيران •

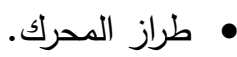
• السمات السطحية للمنطقة حول المطارات.

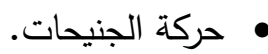

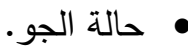
• • الإجراءات المتبعة لإدارة السرعة التي تستخدها الطائرة. • أقصي وزن كلي للطائرة عند الإقلاع. كما تتفاوت نسب الضوضاء بين الطائرات ذات المحركين أو أقل وذات الثلاث محركات

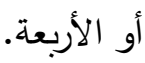
مما سبق يتضح أن هذه المعايير تؤثر علي مدي إنتشار الصوت وبالتالي الحدود

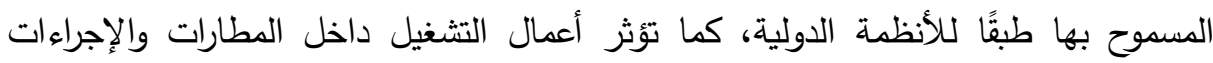
المتبعة للأقلاع ومدي كثافتها وحجمها علي نسب التلوث الضوضائي ويمكن توضيح مصادر الضوضاء الناتجة عن تثغيل الطائرات كما يلي: • الضوضاء الناتجة عن أعمال إقلاع وهبوط الطائرات. • الضوضاء الناتجة عن إستخدام المعدات بغرض نقل الحقائب والركاب.

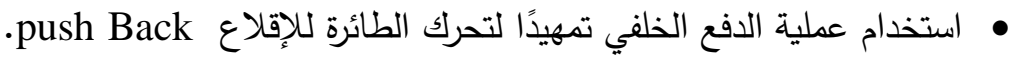

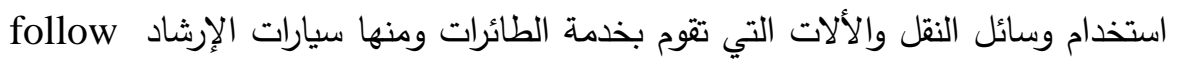
me وسيارات التموين Catering Vehicla. الآلات المستخدمة داخل محطات توليد الطاقة الكهربائية الرئيسية والفرعية.

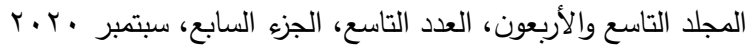

$$
\begin{aligned}
& \text { الترقيم الدولي 0826- ISSN 1110 }
\end{aligned}
$$


• إستخدام سيارات الإطفاء والإسعاف لألأت التتبيه (السارنيه) أثناء حالات الطوارئ. • • الضوضاء الناتجة عن أعمال صيانة الطائرات داخل المطارات.

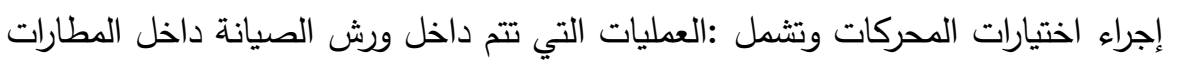

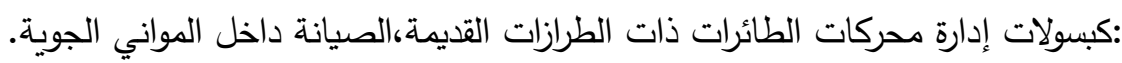
r-التلوث الهوائي الناتج عن تثغيل محركات الطائرات وإنبعاثات عمليات الطيران: (محمد

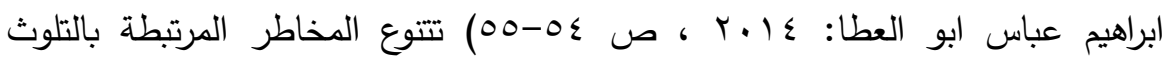
الهوائي نتيجة التطور السريع في صناعة الطيران المدني (عالميً وإقيليميًا ومحليا)، حيث إني أصبح الطيران المدني المحور الأساسي في حياة المجتمعات المتقدمة الحديثة وفي ظل سياسة السماوات المفتوحة وزيادة الحريات والعولمة أصبح له دورًا كبيرًا في التطور الهاتئي

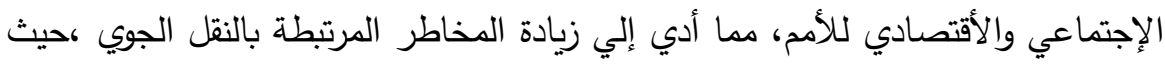
أن العامل الأساسي في دفع عجلة التتمية الأقتصادية في مصر والعالم أجمع، ويمكن توضيح أنواع التلوث المرتبطة بقطاع النقل الجوي كما يلي:

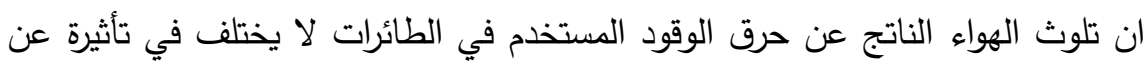

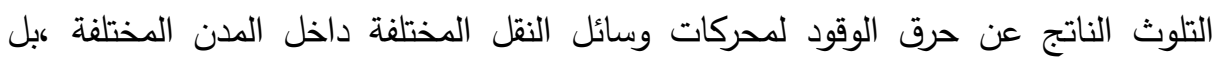
أصبح ينظر إلي إنبعاثات محركات الطائرات علي أنها من أهم مسببات الأضرار الكبيرة والملوثات للغلاف الجوي وذلك لعدة اسباب يمكن توضيحها كما يلي: 1-الزيادة السريعة في حجم الحركة الجوية علي المستوي المحلي والدولي. r- إحتفاظ دول العالم الثالث الفقيرة بعدد كبير من الطائرات ذات الطرازات القديه القديمة والتي ينتج

$$
\text { عن تشغيلها كم هائل من الملوثات الهوائية. }
$$
r-المنافسة الثديدة بين شركات تصنيع الطائرات مما ينتج عن إنتاج حجم هائل من

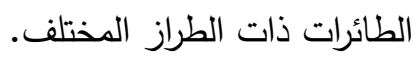

$$
\begin{aligned}
& \text { r. . . المجلد التاسع والأربعون، العدد التاسع، الجزء السابع، سبتمبر }
\end{aligned}
$$

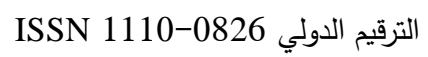




$$
\begin{aligned}
& \text { مجلة العلوم البيئية } \\
& \text { معهد الدراسات والبحوث البيئية - جامعة عين شمس }
\end{aligned}
$$

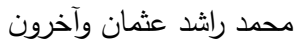

ع - إجراء مزيد من التجارب علي محركات الطائرات المدنية مما ينتج عن تلوث الهواء بكميات

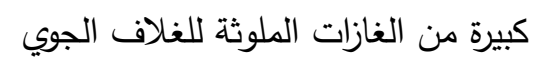

ويمكن توضيح أهم الغازات الضارة الناتجة من إحتراق الوقود نتيجة لتشغيل محركات الطائرات كما يلي:

$$
\begin{aligned}
& \text { أ- اول أكسيد الكربون(CO2). } \\
& \text { ب- ثاني أكسيد الكربون(CO) } \\
& \text { ج- ثاني أكسيد الكبريتٍ (SO }
\end{aligned}
$$

\section{دور التقنيات والتكنولوجيا الحديثة في مواجهة المخاطر والكوارث البيئية:}

: (en.wikipedia.org/wiki/biometric-device : 2019)

إن التخطيط السليم لمواجهة المخاطر والكوارث تتطلب تتفيذ كثير من بنوده استخدام

التقنيات والنماذج الحديثة لتحديد مواقع المخاطر والكوارث ونطاق انتشارها الجغرافي وعمرها وتوقع حدوثها، ومتابعة سيرها، والإنذار والتبليغ بحدوثها، ووسائل المواجهة والتصدي،

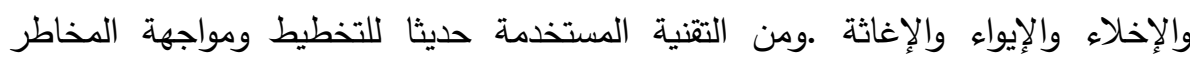

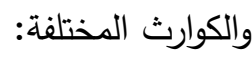
- الكاميرات العالية الدقة والمتصلة بأجهزة حاسبات آلية. - - الرادارات الأرضية والجوية. - - - - السفن و الأقمار الفضائية. - أجهزة الرصد والتسجيل الجوية و الأرضية. - - - - الحواسيب المتقدمة.

- نظم المعلومات الجغرافية(Geographic Information System, GIS - تقنيات الاستثعار عن بعد (Remote Sensing, RS) - - أجزة الاستثعار الذكية.

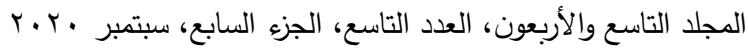

$$
\begin{aligned}
& \text { الترقيم الدولي 0826- ISSN 1110 }
\end{aligned}
$$


- - أجهزة الاتصال السريعة.

اجراءات الحد من مخاطر الضوضاء والانبعاثات الهوائية فى مجال الطيران:

(David Rios Insua : 2013,pp49-54/ Tyler spence : 2016,pp46-48 )

تتضمن المصادر الرئيسية للضوضاء والانبعاثات الهوائية الناتجة عن عمليات تثغيل

الرحلات الجوية محركات الطائرات أثناء الرحلات الجوية والهيوط والاقلاع واستخدام الممرات الرئيسية وتثغيل وحدات الطاقة المساعدة خلال العمليات الأرضية للطائرات وبدء تثغيلها, وتتضمن المصادر الأخرى للانبعاثات الهوائية إفراغ وقود الطائرات النفاثة غير القابل للإحتراق

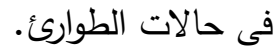

الضوضاء: تتضمن استراتيجيات التعامل مع الضوضاء الموصى بها والتى تعتمد الى حد كبير على متطلبات الإقلاع والهبوط بمطار خاص ما يلى لئى

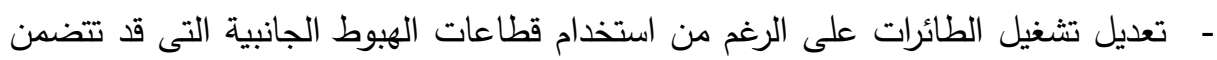
استخدام اجراءات " خفض الطاقة/خفض السحب" لتحليق الطائرة فى حالة صحيحة ( مثال

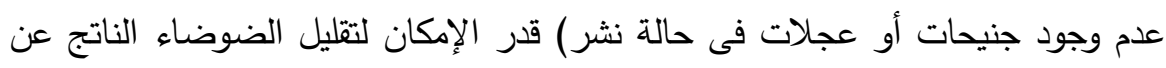

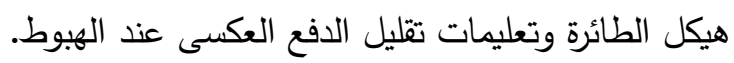

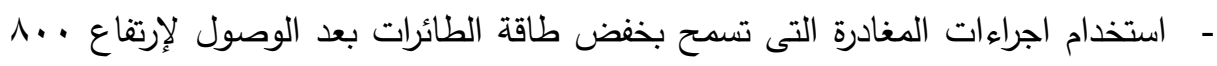

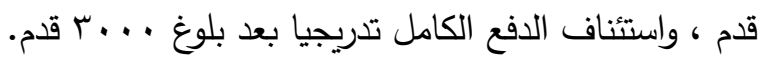

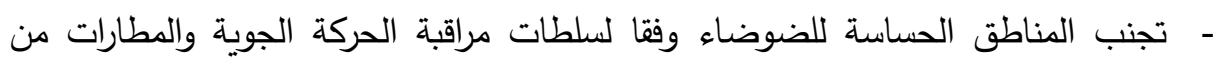
خلال استخدام " الطرق التى تتميز بالضوضاء" والذى يمكن تحقيقة من خلال اجراءات التهاء المغادرة الآلية القياسية (SID) أو عوضا عن ذلك استخدام مسارات الرحلات الجوية المتعددة لتبديد وخفض قوة آثار الضوضاء.

الإنبعاثات الهوائية: ترتبط استراتيجيات خفض وخضن ومنع الانبعارياتات بصورة أساسية بعملية احتراق الوقود ، والتى تعتمد على عدد من العوامل الواردة فى التوصيات التالية : 


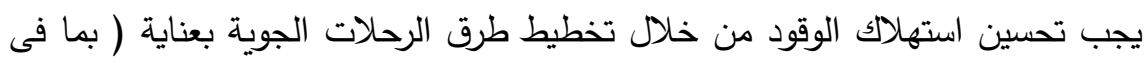

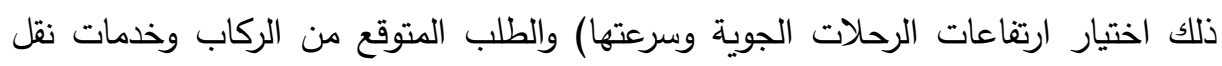

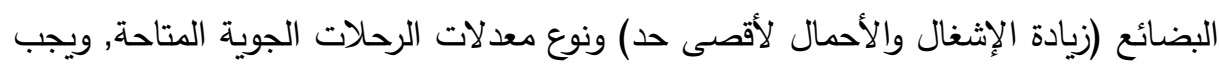

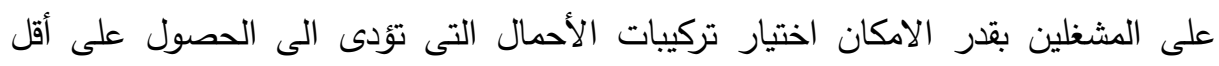
استهالك نوعى للوقود.

Approach مفهوم مدخل الترشيد: لقد تتاولت العديد من الدراسات تعريف مدخل الترشيد Lean

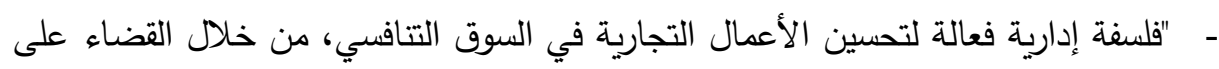

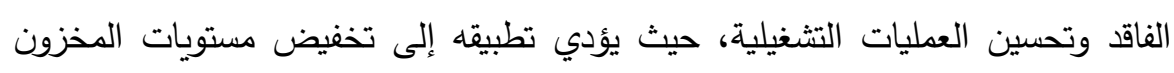
واستبعاد تأثيره على الأرباح، العمل على تحسين ورقابة العمليات وتتظيم أماكن العمل" .(anna dorota rymarzewska: 2016, p1) - مدخل يساعد على توفير إطاراً متكاملاً يتضمن العديد من الأدوات، الأساليب الإحصائية،

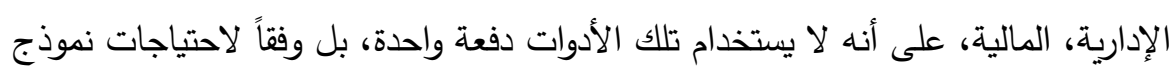
القرار وبشكل يتضمن الحد من التعارض بينها، كذلك يستتد إلى مجموعة من المقومات

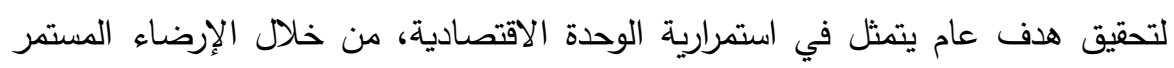

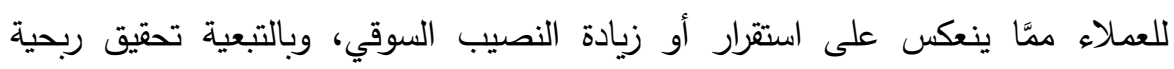

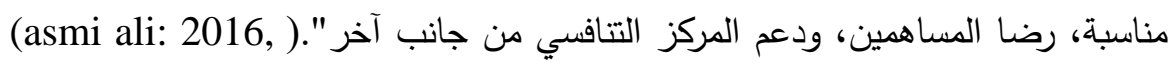

مدخل الترشيد والميزة التنافسية: أدى تزايد الصراع التنافسي لمنظمات الأعمال والتي

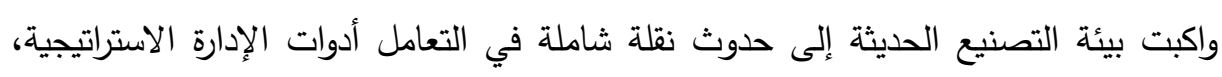

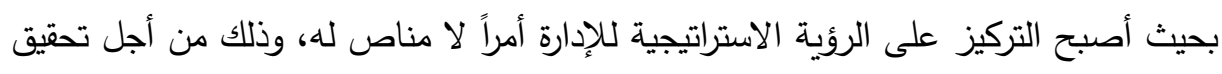

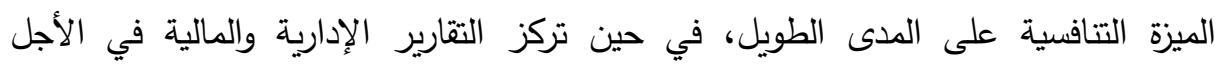

$$
\begin{aligned}
& \text { r. . . • المجلد التاسع والأربعون، العدد التاسع، الجزء السابع، سبتمبر }
\end{aligned}
$$

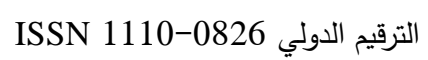


القصير، وبالتالي أصبح النموذج التقليدي للإدارة غير قادر على توفير المعلومات الملائمة

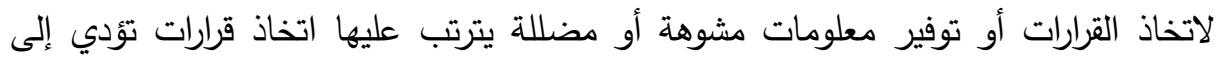

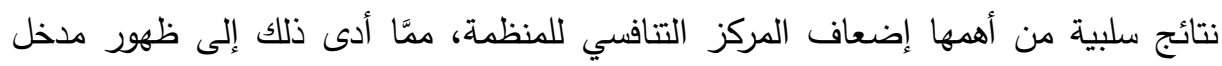

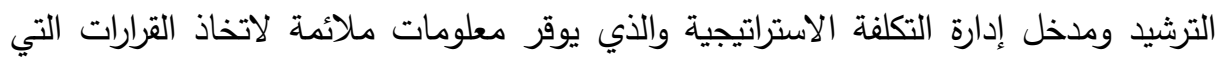
تدعم القدرة التنافسية للمنظمة وبالتالي أصبح مصطلح الاستراتيجية يطلق على المداخل الإدارية الحديثة التي تهتم بأبعاد البيئة التتافسية الخارجية والتخطيط طويل المدى ( asmi) .ali: 2016, p32

دور مدخل الترشيد في دعم القدرة التنافسية: يتمثل دور مدخل الترسيد فى دعم القدرات

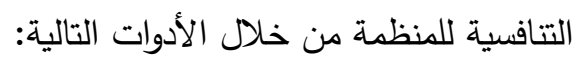
معالجة الفاقد: يعكس مدخل ترشيد قدرة المنظمة على الاستقرار والبقاء وزيادة نصيبها السوقي الاتي من خلال تحقيق الأهداف قصيرة وطويلة الأجل، وتعظيم القيمة المقدمة إلى العملاء، وتعزيز

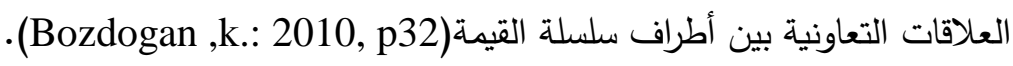
كما أن مدخل ترشيد الفاقد يعد نظام التصنيع الأمثل في القرن الحادي والعشرين؛ حيث العيث لا يبحث عن صفرية الفاقد، ولكنها استراتيجية طويلة المدى نحو التقوق من خلال التحسين التحني

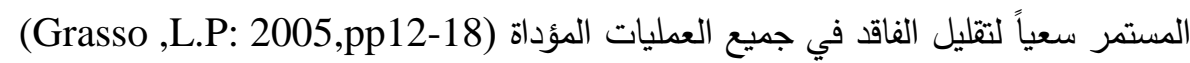

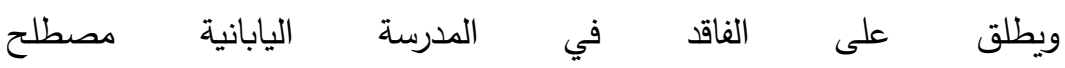
ويتضح أن الفاقد يقصد به كل (http://www.emstrategies.com:2010 (Muda )) شكل من أشكال الفاقد في الموارد المادية والبشرية ، والعيوب في الإنتاج، والتعطيل في سير التير العمليات الإنتاجية؛ مما قد يسبب في ضياع فرص المنظمة، إضافة إلى الصعوبات التي تعيق العمليات المصرفية، وتعيق البنوك للوصول إلى خدمات ذات جودة عالية للعملاء،

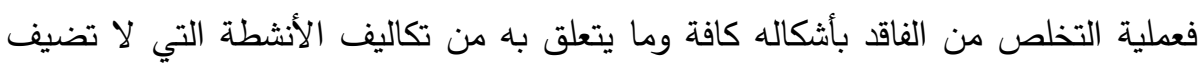

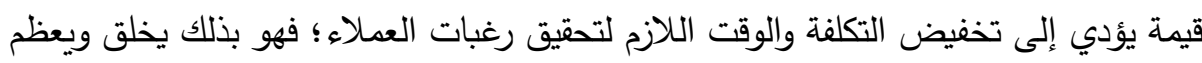

$$
\begin{aligned}
& \text { r. . . المجلد التاسع والأربعون، العدد التاسع، الجزء السابع، سبتمبر }
\end{aligned}
$$

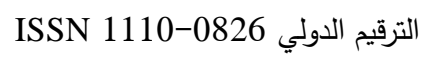


قيمة المنتج لدى العميل، ويساهم في نجاح المنظمة الاقتصادية في تقديم منتج اوخدمة متميزة ذات جودة عالية وبالسعر والوقت المناسب. النتائج المترتبة على التحول إلى مدخل الترشيد: اهتم العديد من الباحثين بدراسة النتائج المترتبة على تحول المنظمات الاقتصادية من تطبيق نظم الإنتاج التقليدية المعتمدة على إنتاج

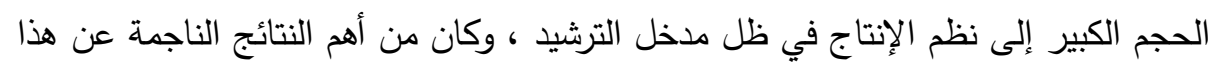

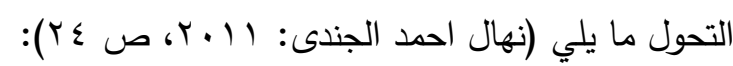

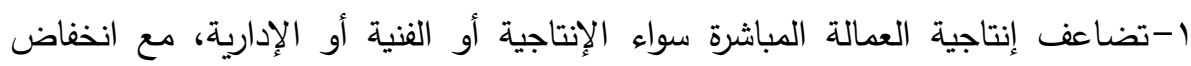
ملموس في حجم المخزون بنفس القيمة تقريباً.

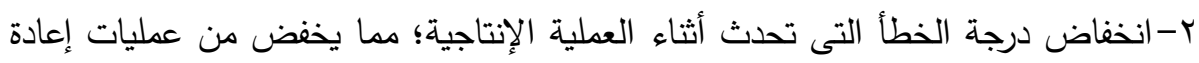

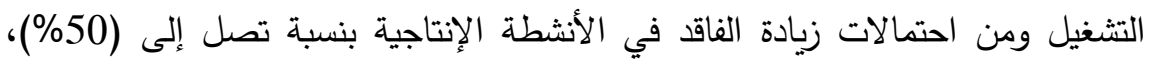
وينعكس ذلك بطبيعة الحال على تحقيق استخدام أمثل للموارد وزيادة القيمة المضافة الإنه المحققة. r-انخفاض زمن استجابة المنتجات لمتطلبات السوق ، وقد سجلت بعض الدراسات انخفاض

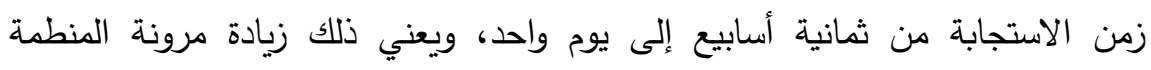

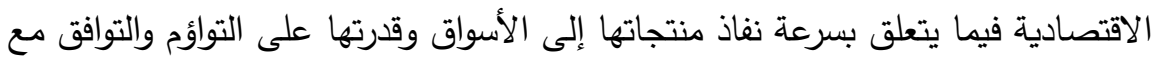
الاحتياجات والرغبات المتجددة للعملاء في مدة زمنية وجيزة ، وبتكلفة اقل . ع-التحسين المستمر KAIZEN : تهذف هذه الاستراتيجية إلى القضاء على الهدر في

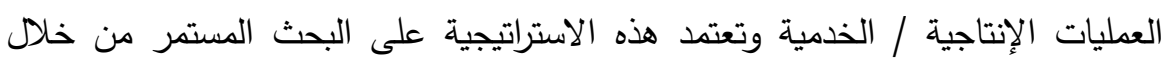

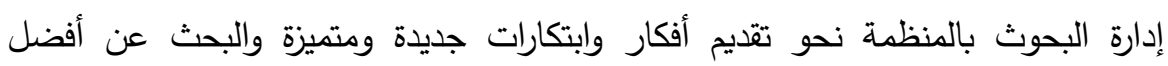

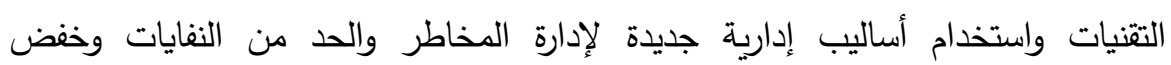
التكاليف بما يؤدي إلى تميز المنظمة وتحقيق عائد أكبر والاستغلال الأمثل لمواردها .(Nur Aishah Binti Awi: 2016, p83)

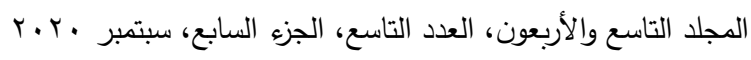

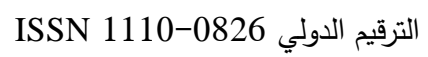


تمتاز هذه الاستراتيجية بالاهتمام بالعنصر البشري من خلال تغيير ثقافة العاملين داخل المنظمة ونشر الوعي لديهم وتقديم الدعم المادي والمعنوي وتتمية مهاراتهم وقدراتهم المختلفة

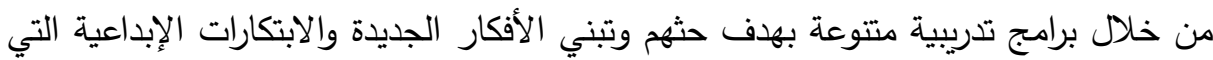
تصب في تطوير وتحسين الأعمال وتصميم طرق ووسائل جديدة لإنجاز المهام والمسئوليات. ترتكز هذه الاسترايتجية على كلاً من: الجودة والتكلفة والتسليه، حيث تؤدي الجودة المتميزة إلى التكلفة الأقل، لأن تحسن الجودة يعني الحد من الفاقد والهدر ، بينما التسليم يعني تقديم المنتج والخدمة إلى العميل في الوقت الذي يطلبه العميل دون تأخير .

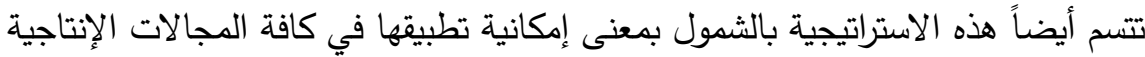
أو الخدمية ولا يقتصر استخدامها على حجم ونوعية المنظمة، فيمكن تطبيق تلك الاستراتيجية في المنظمات والمؤسسات الكبيرة والصغيرة على حد سواء، كما تهتم هذه الاستراتيجية على تحقيق الأهداف على المدى الطويل (Nez Aishah Binti Awi: 2012, p16). وتتميز استراتيجية التحسن المستمر بالعديد من المزايا التي يمكن توضيحها كما يلي:

.(Nez Aishah Binti Awi: 2016, p84) - نشر الوعي وتغيير الثقافة لاى العاملين بالمنظمة. - الاهتمام بمجال البحوث والتطوير ونشر العلم وتبنى الأفكار الجديدة. - تطوير العنصر البشري وتتمية مهاراتهم وقدراتهم الفكرية والإبداعية. - تطوير المنتجات والخدمات من خلال الاهتمام بالقيمة المضافة للمنتج / الخدمة. - تلبية متطلبات العملاء وضمان ولائهم للمنظمة. - تحقيق مكاسب مادية ودعم المركز المالي للمنظمة. - - دعم قدرات المنظفمة للمتنافسين وتحقيق مزايا تنافسية.

$$
\begin{aligned}
& \text { r. r. • المجلد التاسع والأربعون، العدد التاسع، الجزء السابع، سبتمبر }
\end{aligned}
$$

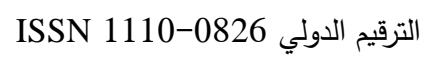




$$
\begin{aligned}
& \text { مجلة العلوم البيئية } \\
& \text { معهد الدراسات والبحوث البيئية - جامعة عين شمس بـ مع } \\
& \text { محمد راشد عثمان وآخرون }
\end{aligned}
$$

استراتيحيات المنافسة الثلاث لبوتر Porter: أطلق بورتر ثلاث استراتيجيات تستخدم في دعم القدرات التتافسية للمنظمة يمكن توضيحها كما يلي: ( Ritika Tan Wal: 2013)

() استراتيجية قيادة التكلفة Cost Strategy) Leadership): تعتمد استراتيجية قيادة التكلفة التي ابتكرها بورتر porter على كل من: - زيادة الربح للمنظمة من خلال التكاليف والبيع بأسعار أقل من المنافسين وتسمى أسعار تنافسية. - زيادة الحصة السوقية من خلال البيع بأسعار أقل والحفاظ في نفس الوقت على ربح منطقي من كل عملية بيع وذلك بسبب خفض التكاليف. وتؤدي هذه الاستراتيجية إلى خفض مستوى الأسعار ، وأضعاف قدرة المنافسين، وتحقيق العديد

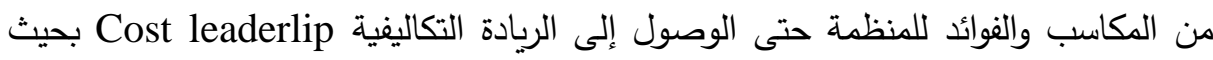
نقل تكلفة المنتج أو الخدمة عن تكاليف الوحدة من المنتج أو الخدمة لدى المنافسين. r) استراتيجية التمييز (Differentiation Strategy): تتضمن تلك الاستراتيجية جعل ونل المنتج أو الخدمة مختلف عن منتجات وخدمات المنافسين بحيث يشمل هذا الاختلاف أو لون التميز على إضافة مواصفات أو خصائص محددة للمنتج أو الخدمة وفي سبيل ذلك فإن وخدان

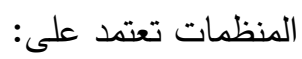

- التطوير والابتكار والبحث المستمر في مواصفات المتنج أو الخدمة ودراسة رغبات العملاء. - القدرة على تقديم المنتج أو الخدمة بجودة تقوق توقعات العملاء. - قدرة المنظمة على استيعاب الحصة السوقية من خلال البيع والتسويق والمستهلكين.

$$
\begin{aligned}
& \text { r. r. • المجلد التاسع والأربعون، العدد التاسع، الجزء السابع، سبتمبر }
\end{aligned}
$$

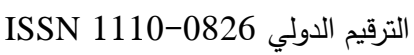


ويمكن للمنظمات التي تتبع هذه الاستراتيجية فرض أسعار أعلى من المنافسين نتيجة

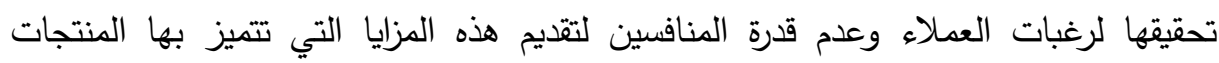
والخدمات. r) استراتيجية التركيز (Focus Strategy): تعتمد هذه الاستراتيجية على التركيز على مجموعة محددة من الأسواق أو التركيز على نوعية محددة من العملاء وتطوير المنتجات والخدمات بما يلائم ويحقق الرغبات والمتطلبات التي يحتاجها هؤلاء العملاء.

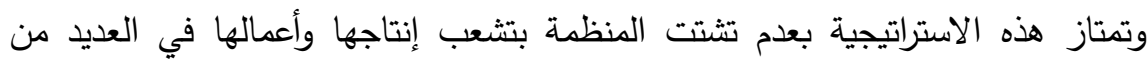

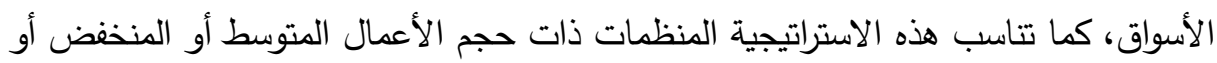
ذات الموارد المحدودة ولا تستطيع تغطية حجم كبير من الأسواق. خفض وقت العمليات: (Asmi Ali: 2016,p26) يعد الاهتمام بعنصر الوقت أحد الأهداف كنواف الرئيسية التي تهتم بها مدخل الترشيد، كما يعتبر الوقت عنصر تتافسي للمنظمة من خلال

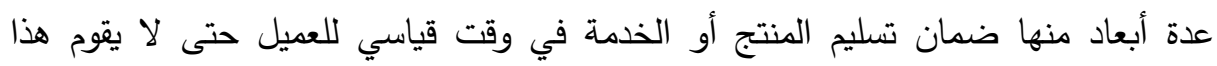
العميل بالبحث عن مصادر أخرى لإثباع احتياجاته ورغباته، وفي نفس الوقت فإن إن التأخير في الاعمال يتسبب في ارتفاع التكاليف وضعف الموقف التتافسي للمنظمة، تتجلى قدرة أي الئهي منظمة على مدى المرونة في خفض الوقت المستتف في الإنتاج وفي الوقت اللازم لتسويق وبيع منتجاتها وخدماتها، ومن هنا ييرز دور منهجية الترشيد من تخفيض الوقت التهن اللازم لأداء العمليات المختلفة المرتبطة بالخدمة أو المنتج من خلال المحاور التالية: - وضع خريطة تمثل خطوات الأعمال المختلفة لتقديم المنتج أو الخدمة.

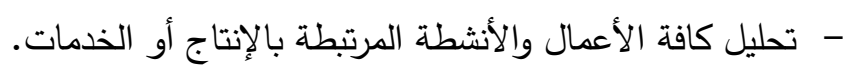
- خفض الوقت اللازم في كافة مراحل الإنتاج التي تولد قيمة مضافة للمنتج أو الخدمة.

$$
\begin{aligned}
& \text { r. r. • المجلد التاسع والأربعون، العدد التاسع، الجزء السابع، سبتمبر }
\end{aligned}
$$

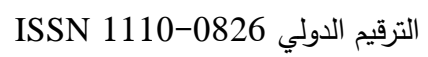




\section{إلجراعاهي اللهمث}

( ) قام الباحث - بعد تصميم قائمة الاستقصاء وأخذ الموافقة على استخدامها - بتوزيع قائمة الاستقصاء على عينة البحث، وبعد إعطائهم الوقت الكافي والتأكد من استيفائها، قام الباحث بجمع تلك القوائم ومراجعتها، واستبعاد غير الصالح منها للتحليل. بام الباحث بترميز أسئلة قائمة الاستقصاء، حيث تم تعريف متغيرات البحث، وذلك بترميز المتغير المستقل بالرمز X، وترميز المتغير الوسيط بالرمز M، والمتغير التابع بالرمز Y، كما تم إعطاء رقم لكل سؤال يشير إلى رقم المحور ثم رقم العبارة داخل المحور ، كما تم

$$
\text { بترقيم قوائم الاستقصاء ليسهل الرجوع إليها عند الحاجة. }
$$

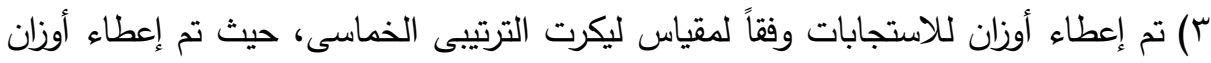

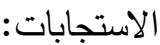

غير موافق مطلقاً
بعد أخذ المتوسط المرجح للاستجابات تم تقسيم هذا المدى على درجات الموافقة، حيث

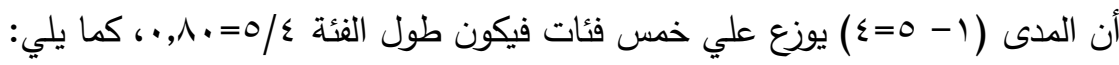

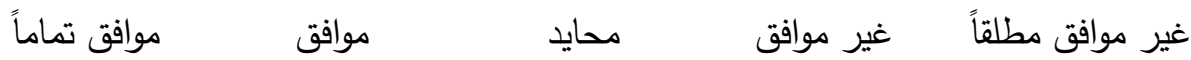
$0-\varepsilon, r . \quad \varepsilon, 19-r, \varepsilon . \quad r, r q-r, r . \quad r, 09-1, \Lambda . \quad 1, \vee q-1$

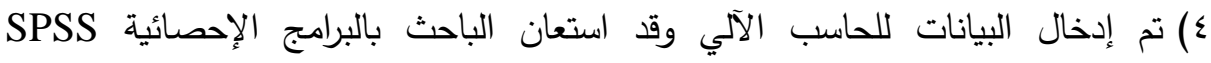

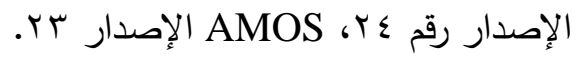

0) تم تحليل البيانات، واستخلاص النتائج، وإصدار التوصيات في ضوء تلك الإصنائج.

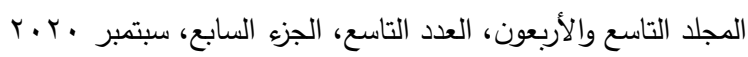

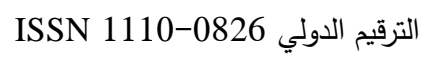


مجلة العلوم البيئية

معهد الدراسات والبحوث البيئية - جامعة عين شمس لبه

محمد راشد عثمان وآخرون

نتائج خاصة بالبيانات الايموجرافية لعينة البحث الأصلية:

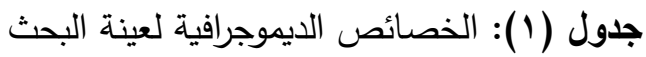

\begin{tabular}{|c|c|c|c|}
\hline نسبة \% & عدد & الفئات & الخصائص \\
\hline vo,. & IrT & بكالوريوس & \multirow{4}{*}{ التعليميتوى } \\
\hline r),r & ro & ماجستير & \\
\hline$r, \varepsilon$ & $\varepsilon$ & دكتوراه & \\
\hline $1, r$ & r & شهادات مهنية & \\
\hline$r \cdot, 0$ & 0 . & موظف & \multirow{7}{*}{ الوظيفة } \\
\hline$\Lambda, 0$ & $1 \varepsilon$ & محاسب & \\
\hline$I V, V$ & rq & مهندس & \\
\hline ro, & $\leqslant 1$ & رئيس قسم & \\
\hline 10,9 & ry & مدير إدارة & \\
\hline $1, Y$ & $r$ & مدير عام & \\
\hline $1, r$ & r & رئيس قطاع & \\
\hline$\vee, r$ & ir & من سنة - 0 سنوات & \multirow{7}{*}{ سنوات الخبرة } \\
\hline$r \wedge, V$ & $\varepsilon V$ & من 7 سنوات - ، 1 سنوات & \\
\hline$r T, r$ & rᄉ & من | 1 سنة - 10 سنة & \\
\hline $1 \wedge, r$ & $r$. & من 71 سنة - . r سنة & \\
\hline \multirow[t]{3}{*}{$r r, 7$} & $r v$ & أكثر من · r سنة & \\
\hline & & الوسط الحسابي = ع ا سنة & \\
\hline & & الانحراف المعياري = ع, 7 سنة & \\
\hline $1 \cdots$ & $17 \varepsilon$ & الإجمالى & \\
\hline
\end{tabular}

أظهرت نتائج تحليل البيانات الديموجرافية لعينة البحث من حيث المؤهل العلمي: بلغت

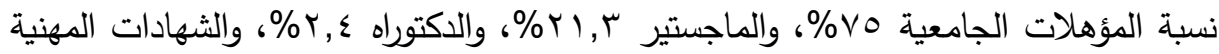

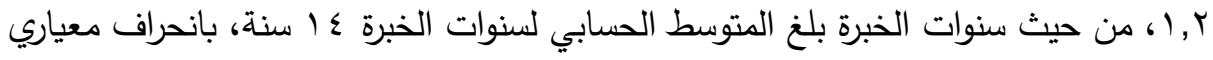
قدره ؟,7 سنة. ومن حيث الوظيفة كانت نسبة الموظفين، رؤساء الأقسام، والمهندسين،

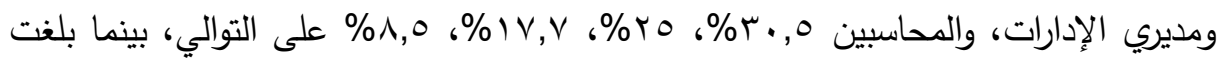
نسبة المدير العام ورئيس قطاع r, , ا \% لكلٍ منهما.

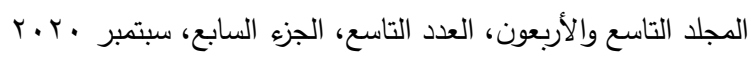


مجلة العلوم البيئية

معهد الدراسات والبحوث البيئية - جامعة عين شمس البية

محمد راشد عثمان وآخرون

نتائج خاصة باختبارات الثبات لبيانات البحث:

جدول (r): مقاييس الثبات Reliabilty لمتغيرات البحث

\begin{tabular}{|c|c|c|c|}
\hline الصدق (") & $\begin{array}{l}\text { Alfa } \\
\text { Alمل الثبات }\end{array}$ & 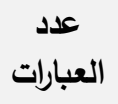 & 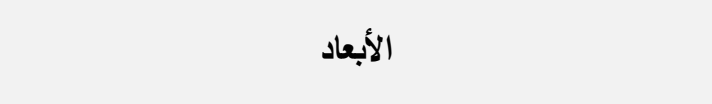 \\
\hline$\cdot, 9 Y 7$ & $\cdot, 101$ & r & إدارة وضبط الدخاطر البيئية في قطاع النقل الجوي \\
\hline$\cdot, 94$ & $\cdot$, Атт & rV & مدخل الترشيد (Lean Approach) \\
\hline$\cdot, 9$ \% & $\cdot, \wedge \vee \varepsilon$ & r & مدي أهمية القدرة التتافسية المستدامة فى قطاع النقل الجوى \\
\hline$\cdot, 919$ & $\cdot, \wedge \leq 0$ & 11 & الترشيد لدعم القدرة التتافسية المستدامة بقبط البيأية باستخدام النفل الجوىل \\
\hline$\cdot, \wedge \leqslant \wedge$ & $\cdot, \wedge ৭ \wedge$ & 97 & قئمة الاستقصاء ككل \\
\hline
\end{tabular}

(") معامل الصدق هو الجذر التربيعي لمعامل الثبات، ويقصد به الصدق البنائي أظهرت نتائج

الاتساق الداخلي أن أبعاد البحث تقيس ما وضعت لقياسة، حيث كانت معاملات الارتباط بين

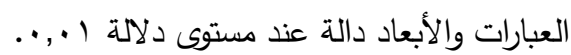

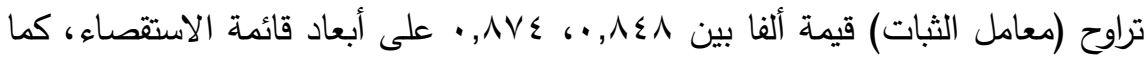

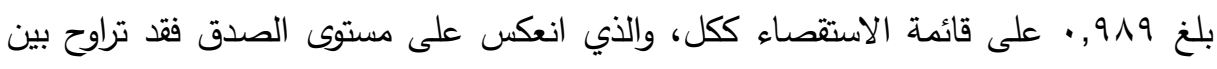

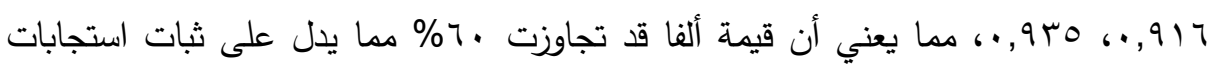

العينة وإمكانية تعميمها على مجتمع البحث. 
مجلة العلوم البيئية

معهد الدراسات والبحوث البيئية - جامعة عين شمس لئة

محمد راشد عثمان وآخرون

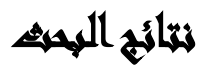

جدول (ץ): نتائج خاصة بتوصيف متغيرات البحث: الإحصاء الوصفي لمحور إدارة وضبط المخاطر البيئية

\begin{tabular}{|c|c|c|c|c|c|c|}
\hline 争: & $\frac{3}{\bar{T}}$ & 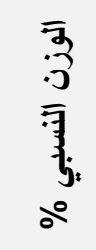 & 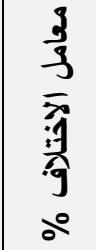 & 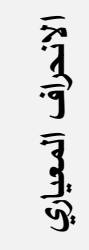 & $\begin{array}{l}\overline{7} \\
\overline{3} \\
\overline{7} \\
\overline{7} \\
3 \\
\overline{3}\end{array}$ & $\frac{\overline{3}}{3}$ \\
\hline$r$ & 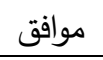 & $\Lambda r, r$ & $r r, 0$ & $\cdot, 9 \leqslant$ & $\{, 17$ & تهنم الثركة بإدارة الدخاطر البيئية؟ \\
\hline 0 & 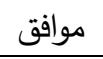 & $\Lambda r, T$ & $r r, 0$ & $\cdot, 9 \vee$ & $\varepsilon, 1 \mu$ & تلتزم الثركة بالقوانين والتشريعات البيئية؟ X2 \\
\hline 1 & موافتّ & $\wedge \vee, \varepsilon$ & $r \cdot, l$ & $\cdot, \wedge \wedge$ & $\varepsilon, r V$ & 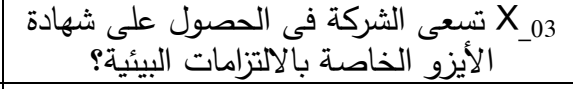 \\
\hline 1. & 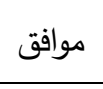 & $\Lambda_{\cdot}, \varepsilon$ & $r_{0,0}$ & $1, \cdot r$ & $\varepsilon, \cdot r$ & 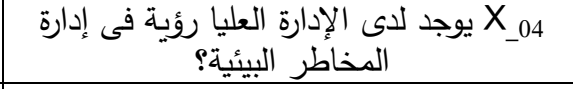 \\
\hline 19 & 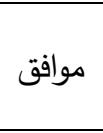 & $V r, r$ & $r v, r$ & $1, \ldots$ & $r, 74$ & 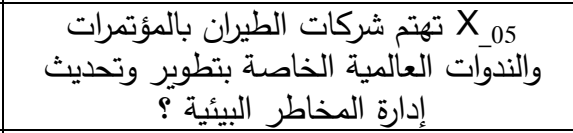 \\
\hline ro & 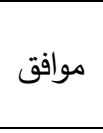 & $V \cdot, r$ & $r \varepsilon, \Lambda$ & $\cdot, \wedge \vee$ & $r, 01$ & 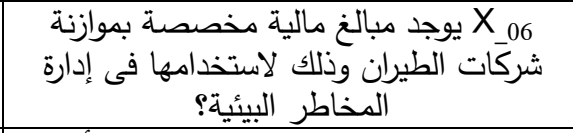 \\
\hline IV & 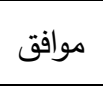 & $V \varepsilon, Y$ & $r 0, r$ & $\cdot, 9 \leq$ & $r, v)$ & يوجد تحديث وتطوير مستمر فى أجهزة الرصئئ X_07 \\
\hline 17 & 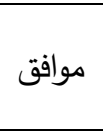 & $V_{0}, \varepsilon$ & $r \leqslant, V$ & $\cdot, 94$ & $r, V \gamma$ & 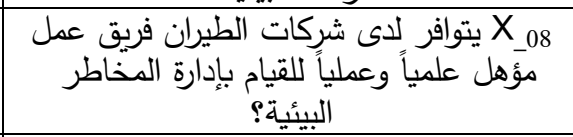 \\
\hline$r$. & 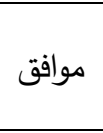 & $V Y, T$ & $r O, r$ & $\cdot, 91$ & r, & 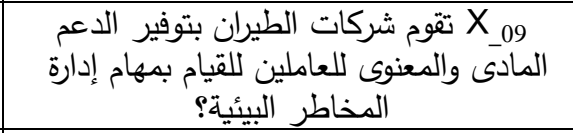 \\
\hline 10 & 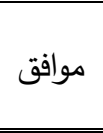 & $v_{0,7}$ & $r \uparrow, v$ & $1, \cdot 1$ & $r, \vee \wedge$ & 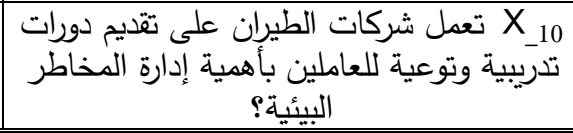 \\
\hline
\end{tabular}


مجلة العلوم البيئية

معهد الدراسات والبحوث البيئية - جامعة عين شمس لئه

محمد راشد عثمان وآخرون

\begin{tabular}{|c|c|c|c|c|c|c|}
\hline 争: & $\frac{3}{3}$ & 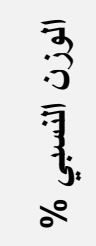 & $\begin{array}{l}3 \\
3 \\
\frac{3}{3} \\
\frac{1}{3} \\
\text { o0 }\end{array}$ & $\begin{array}{l}\overline{7} \\
\frac{3}{9} \\
\overline{3} \\
\frac{3}{9}:\end{array}$ & $\begin{array}{l}\overline{7} \\
\overline{3} \\
\overline{7} \\
\overline{3} \\
3 \\
\overline{3}\end{array}$ & 亨. \\
\hline 9 & موافق & $\Lambda \cdot, \Sigma$ & $r r,$. & $\cdot, q r$ & $\varepsilon, \cdot r$ & 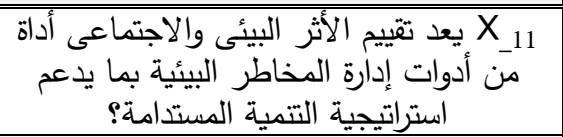 \\
\hline YI & موافق & $V Y, Y$ & $r \wedge, l$ & $1, \cdot r$ & rד, & 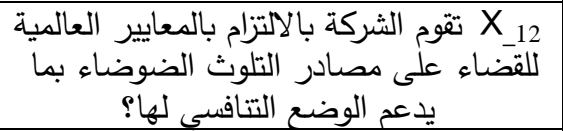 \\
\hline rr & موافق & $\vee \backslash, \Lambda$ & $r \wedge, r$ & $1, \cdot 1$ & $r, 09$ & 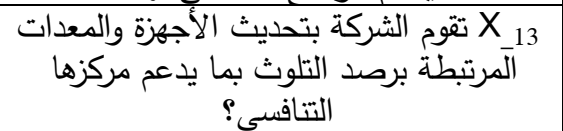 \\
\hline$\Lambda$ & موافق & $\wedge 1$, & $19, r$ & $\cdot, \vee \wedge$ & $\varepsilon, 0$ & 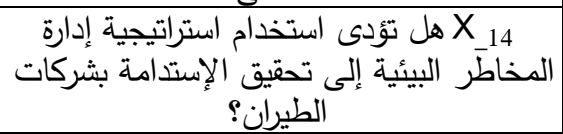 \\
\hline$r \leq$ & موافق & $\vee \cdot, \Lambda$ & $r V, r$ & $\cdot, 9 V$ & $r, 0 \leqslant$ & 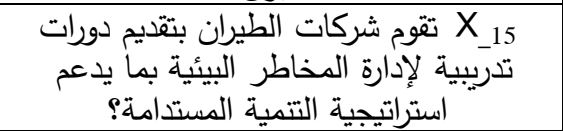 \\
\hline 7 & موافق & $\wedge r, \Sigma$ & $r \cdot, T$ & $\cdot, \wedge 0$ & $\varepsilon, \mid Y$ & 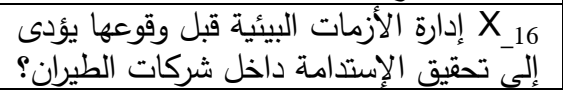 \\
\hline $1 \varepsilon$ & موافق & $V 7, \varepsilon$ & Yo,, & $\cdot, 99$ & $r, \wedge r$ & 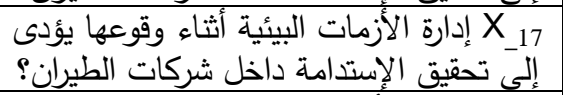 \\
\hline rr & موافق & $V I, r$ & $r, q$ & $1,1 V$ & r,0 & 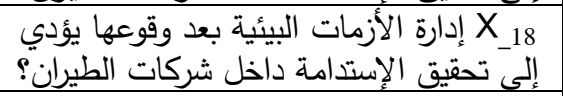 \\
\hline$\varepsilon$ & موافق & $\wedge r, \tau$ & $1 \wedge$, & $\cdot, \vee \vee$ & $\varepsilon, 1 T$ & 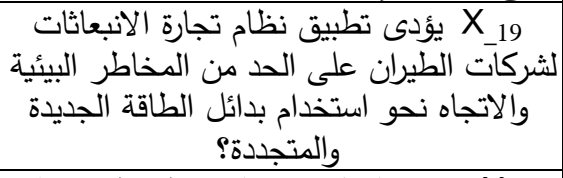 \\
\hline V & موافق & $\wedge), \wedge$ & $r \varepsilon, T$ & $1, \cdot 1$ & $\varepsilon, \cdot 9$ & 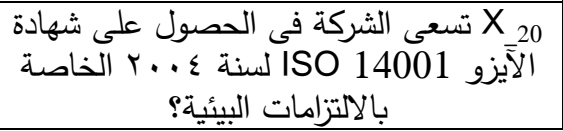 \\
\hline
\end{tabular}

588

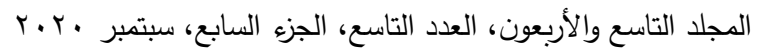

الترقيم الدولي 0826-0 الإنوني 
مجلة العلوم البيئية

معهد الدراسات والبحوث البيئية - جامعة عين شمس لئة

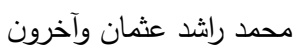

\begin{tabular}{|c|c|c|c|c|c|c|}
\hline 青! & $\frac{3}{3}$ & 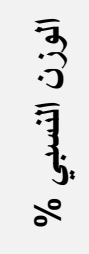 & $\begin{array}{l}\frac{3}{3} \\
\frac{3}{3} \\
\frac{1}{7 y} \\
\frac{9}{9} \\
\circ\end{array}$ & $\begin{array}{l}\overline{7} \\
\overline{3} \\
\overline{9} \\
\overline{3} \\
\frac{3}{9} \\
\overline{9}\end{array}$ & $\begin{array}{l}\overline{3} \\
\frac{3}{3} \\
\overline{3} \\
\frac{3}{3}\end{array}$ & 高. \\
\hline$r$ & جدواً & $\wedge \neg, \wedge$ & $10, r$ & & $\varepsilon, \Gamma \varepsilon$ & 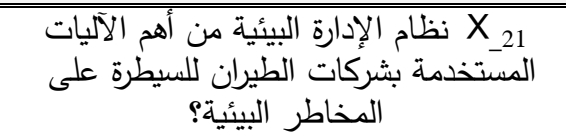 \\
\hline $1 \pi$ & موافق & $\vee q, \varepsilon$ & $r_{1,9}$ & $\cdot, \wedge \vee$ & $r, 9 v$ & 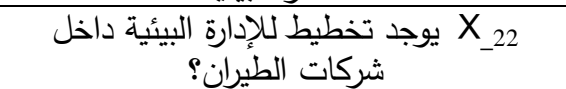 \\
\hline$M$ & موافق & $\vee ৭, \wedge$ & 19,7 & $\cdot, \vee \wedge$ & $r, 99$ & 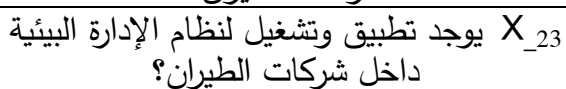 \\
\hline 11 & موافق & $\Lambda \cdot, r$ & $1 \wedge, 7$ & $\cdot, \vee_{0}$ & $\varepsilon, \cdot 1$ & 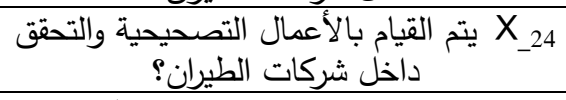 \\
\hline 11 & موافق & $V \Gamma, \Lambda$ & Tr, & $\cdot, \wedge \vee$ & $r, 7 q$ & 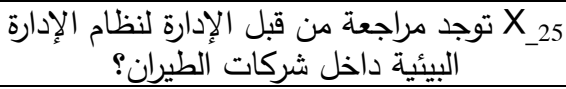 \\
\hline \multirow[t]{2}{*}{$r 4$} & موافق & $V Y_{,} \cdot$ & $r, r$ & $\cdot, V 4$ & r. & 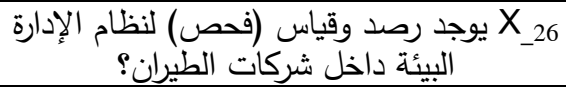 \\
\hline & موافق & $V V, \tau$ & 17,0 & $\cdot, 7 \leqslant$ & $r, \wedge \wedge$ & 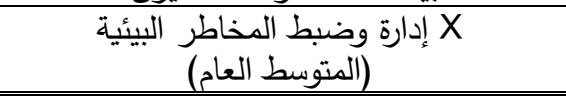 \\
\hline
\end{tabular}

جاءت درجة الموافقة "موافق" على محور إدارة وضبط المخاطر البيئية (المتوسط العام)،

كما جاءت درجة الموافقة "موافق جداً"على العناصر التالية:

- تسعى الشركة فى الحصول على شهادة الأيزو الخاصة بالالتزامات البيئية.

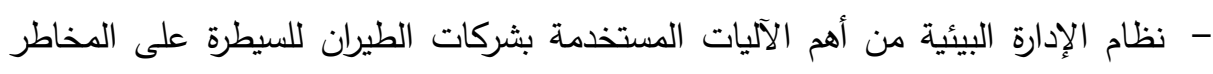
البيئية. • جاءت درجة الموافقة "موافق" على العناصر التالية، وقد جاءت مرتبة وفقاً لأهميتها من

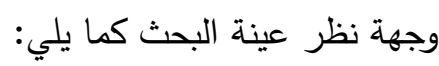
- تهتم الشركة بإدارة المخاطر البيئية 


$$
\begin{aligned}
& \text { مجلة العلوم البيئية } \\
& \text { معهد الدراسات والبحوث البيئية - جامعة عين شمس بـ مع } \\
& \text { محمد راشد عثمان وآخرون }
\end{aligned}
$$

- يؤدى تطبيق نظام تجارة الانبعاثات لشركات الطيران على الحد من المخاطر البيئية

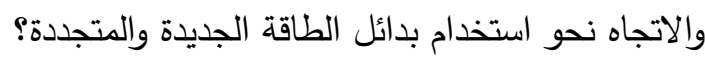

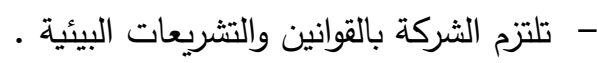

- - إدارة الأزمات البيئية قبل وقوعها يؤدى إلى تحقيق الاستدامة داخل شركات الطيران.

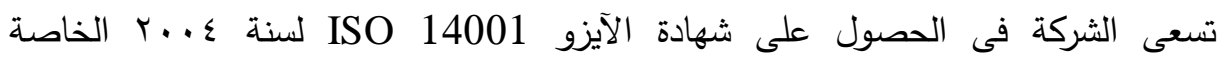
بالالتزامات البيئية.

- تؤدى استخدام استراتيجية إدارة المخاطر البيئية إلى تحقيق الاستدامة بشركات الطيران.

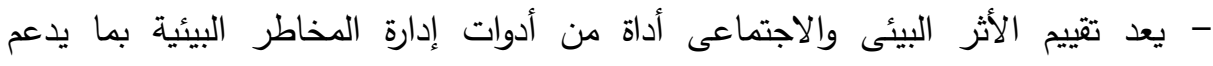

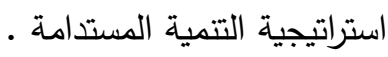

- يوجد لاى الإدارة العليا رؤية فى إدارة المخاطر البيئية . - يتم القيام بالأعمال التصحيحية والتحقق داخل شركات الطيران.

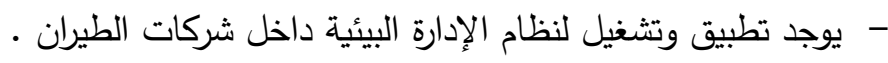
- يوجد تخطيط للإدارة البيئية داخل شركات الطيران.

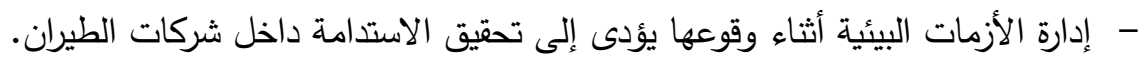

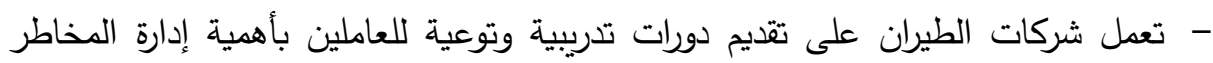
البيئية.

- يتوافر لدى شركات الطيران فريق عمل مؤهل علمياً وعملياً للقيام بإدارة المخاطر البيئية. - يوجد تحديث وتطوير مستمر فى أجهزة الرصد البيئية.

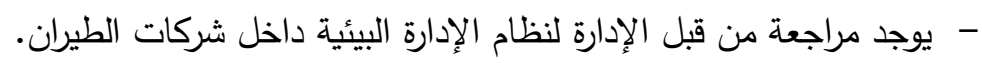
- تهتم شركات الطيران بالمؤتمرات والندوات العالمية الخاصة بتطوير وتحديث إدارة المخاطر البيئية.

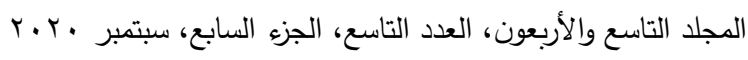

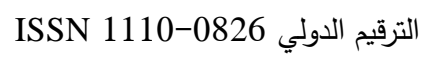




$$
\begin{aligned}
& \text { مجلة العلوم البيئية } \\
& \text { معهد الدراسات والبحوث البيئية - جامعة عين شمس لكس }
\end{aligned}
$$

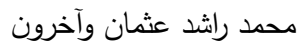

- تقوم شركات الطيران بتوفير الدعم المادى والمعنوى للعاملين للقيام بمهام إدارة المخاطر

$$
\text { البيئية. }
$$

- تقوم الثركة بالالتزام بالمعايير العالمية للقضاء على مصادر التلوث الضوضاء بما يدعم

$$
\text { الوضع التتافسى لها. }
$$

- يوجد رصد وقياس (فحص) لنظام الإدارة البيئة داخل شركات الطيران.

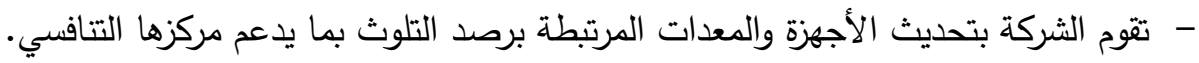
- إدارة الأزمات البيئية بعد وقوعها يؤدي إلى تحقيق الاستدامة داخل شركات الطيران. - تقوم شركات الطيران بتقديم دورات تدريبية لإدارة المخاطر البيئية بما يدعم استراتيجية التتمية المستدامة.

يوجد مبالغ مالية مخصصة بموازنة شركات الطيران وذلك لاستخدامها فى إدارة المخاطر البيئية. جدول (؛): الإحصاء الوصفي لمدخل الترشيد

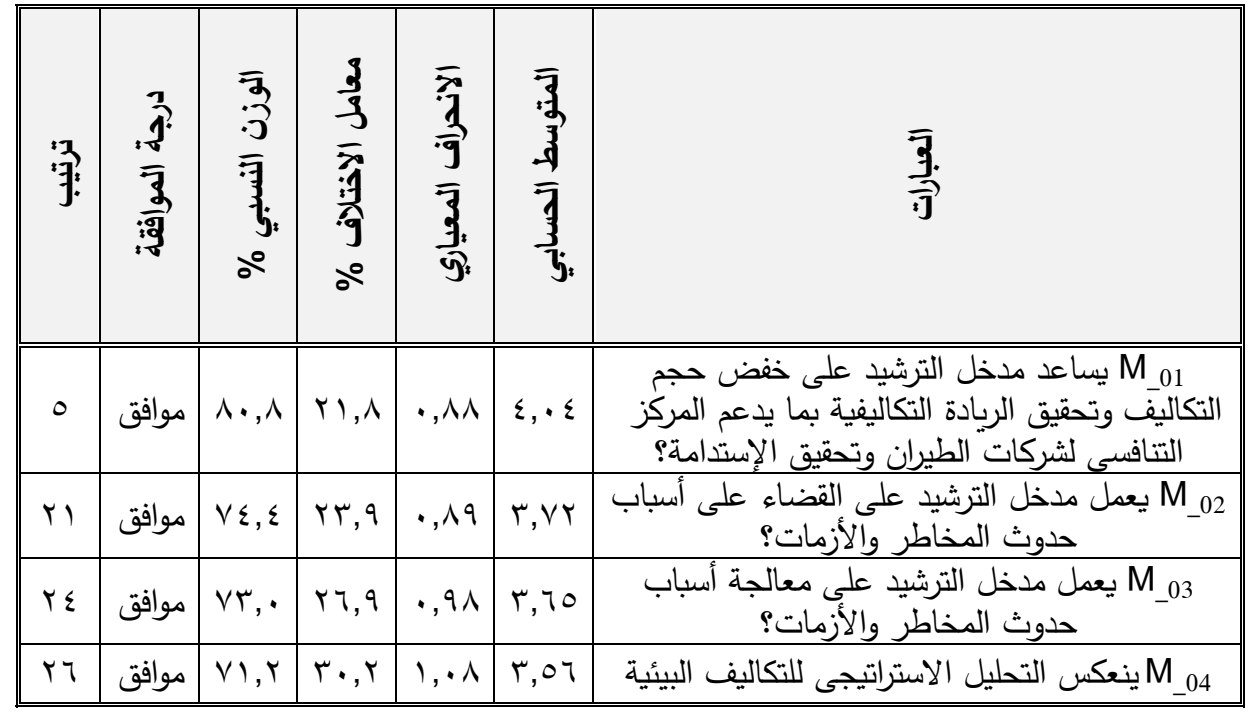

r. r. • المجلد التاسع والأبعون، العدد التاسع، الجزء السابع، سبتمبر 
مجلة العلوم البيئية

معهد الدراسات والبحوث البيئية - جامعة عين شمس لئن

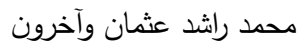

\begin{tabular}{|c|c|c|c|c|c|c|}
\hline 争: & 高 & 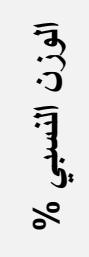 & $\begin{array}{l}\frac{3}{3} \\
\frac{3}{3} \\
\frac{9}{9} \\
\frac{9}{9}\end{array}$ & 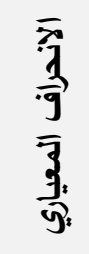 & $\begin{array}{l}\overline{3} \\
\frac{3}{3} \\
\overline{3} \\
\frac{3}{3}\end{array}$ & 高. \\
\hline & & & & & & 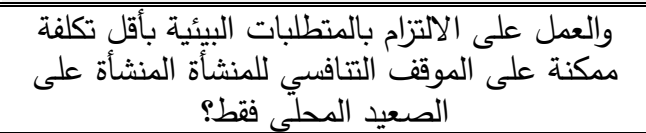 \\
\hline TV & 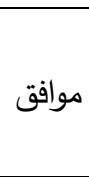 & 79,1 & $r v, \varepsilon$ & $\cdot, 97$ & r, $\leqslant q$ & 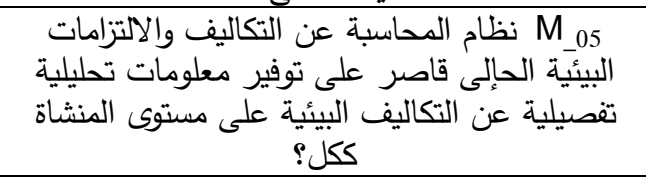 \\
\hline$r$ & 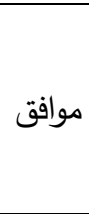 & $\wedge r, \cdot$ & $\mid \Lambda, r$ & $\cdot$, vo & $\varepsilon, 1$. & 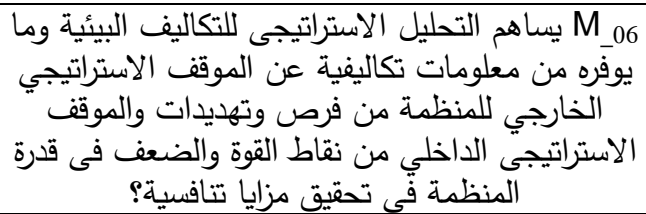 \\
\hline V & 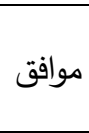 & $\vee 9, \wedge$ & $r \varepsilon, 1$ & $\cdot, 97$ & $r, 99$ & 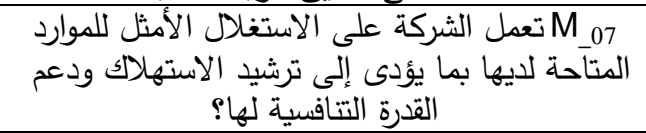 \\
\hline 11 & موافق & $V \vee, \Lambda$ & $r v, \cdot$ & $1, .0$ & $r, \wedge 9$ & 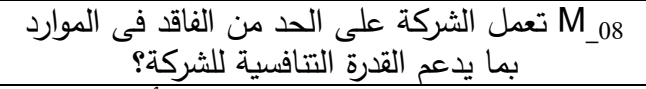 \\
\hline 9 & 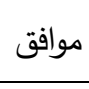 & $\vee q, \varepsilon$ & $r_{0,0}$ & $1, \cdot 1$ & $r, 9 \vee$ & 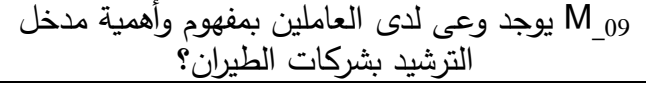 \\
\hline rr & 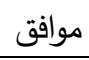 & $V \varepsilon, r$ & ro,1 & $\cdot, 94$ & $r, v)$ & تهتم شركات الطيران العربية بدخل الترشيد؟ \\
\hline$r$ & 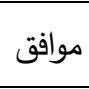 & $V \varepsilon, Y$ & $r 7,9$ & $1, \cdots$ & $r, v)$ & 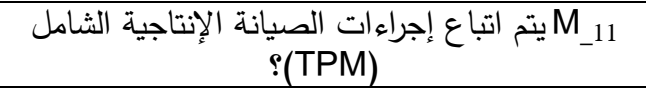 \\
\hline 17 & 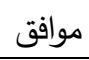 & $\vee \neg, \Lambda$ & rı, r & $1, \cdot 1$ & $r, \wedge \varepsilon$ & Mت تتم مراجعة إجراءات الحد من كافة أنواع الفاقد؟ \\
\hline IV & 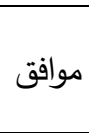 & $\vee \curlyvee, \varepsilon$ & $r T, 0$ & $\cdot, 9$. & r,Ar & 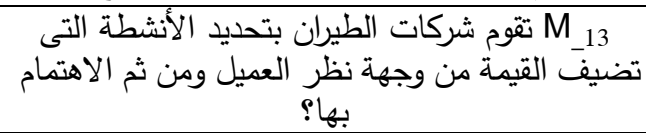 \\
\hline 19 & موافق & V५, & $r_{0, \Sigma}$ & $\cdot, 9 \mathrm{~V}$ & $r, \Lambda$. & تقوم شركات الطيران بإلغاء الأنشطة التى لا M_14 \\
\hline
\end{tabular}

592

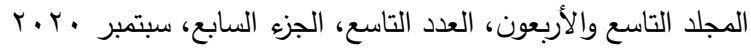

الترقيم الدولي 0826- ISSN 1110 
مجلة العلوم البيئية

معهد الدراسات والبحوث البيئية - جامعة عين شمس لئن

محمد راشد عثمان وآخرون

\begin{tabular}{|c|c|c|c|c|c|c|}
\hline 净: & $\frac{3}{3}$ & 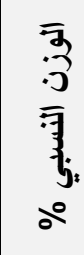 & $\begin{array}{l}\frac{3}{3} \\
\frac{3}{3} \\
\text { 得 } \\
\text { d0 }\end{array}$ & 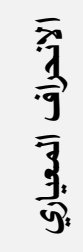 & $\begin{array}{l}\overline{7} \\
3 \\
\overline{3} \\
\overline{7} \\
3 \\
3\end{array}$ & $\overline{\overline{3}}$ \\
\hline & & & & & & تضيف قيمة من وجهة نظر العملاء؟ \\
\hline$r$ & موافق & $\wedge 1$, & 11, & $\cdot, V T$ & $\varepsilon, .0$ & 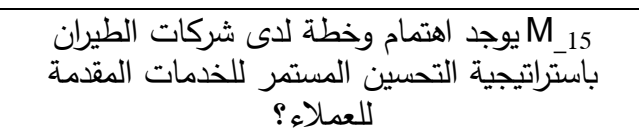 \\
\hline 11 & موافق & 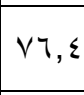 & $r \leqslant, \Lambda$ & $\cdot, 90$ & $r, \wedge r$ & 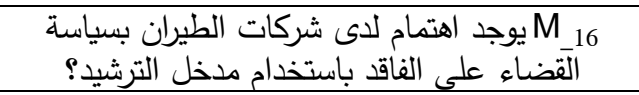 \\
\hline ro & موافق & $v 1, r$ & rq, & $1, \cdot r$ & $r, 07$ & 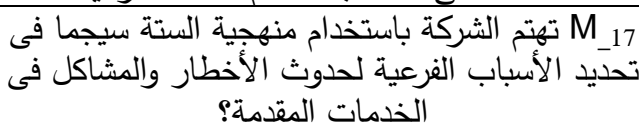 \\
\hline$r$. & موافق & $v_{0}, 7$ & $r V, r$ & $1, \cdot r$ & 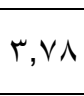 & 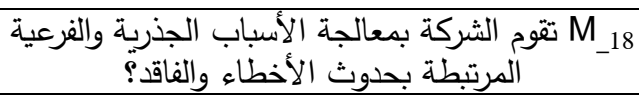 \\
\hline 1. & موافق & $\vee q, \cdot$ & Yo, $V$ & $1, \cdot 1$ & $r, 90$ & 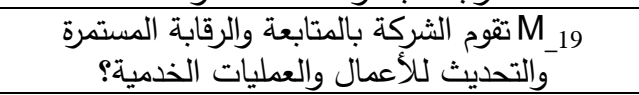 \\
\hline$\varepsilon$ & موافق & $\wedge 1, \cdot$ & 11,9 & $\cdot, \mathrm{VV}$ & $\varepsilon, .0$ & 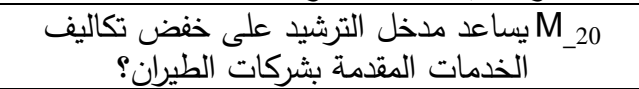 \\
\hline 7 & موافق & $\Lambda \cdot, \cdot$ & $r \cdot, r$ & $\cdot, \lambda)$ & $\varepsilon, \cdots$ & 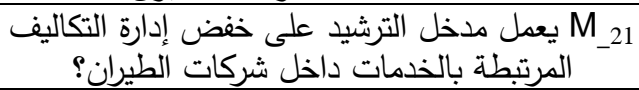 \\
\hline $1 \varepsilon$ & موافق & $\nabla V, \varepsilon$ & $r \cdot, V$ & $\cdot, \wedge$. & $\Gamma, \wedge \vee$ & 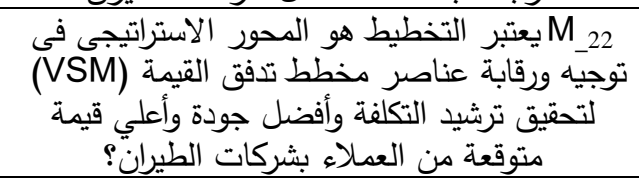 \\
\hline 1 & 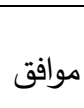 & $\Lambda r, r$ & $1 v, 0$ & $\cdot, V T$ & $\varepsilon, 17$ & 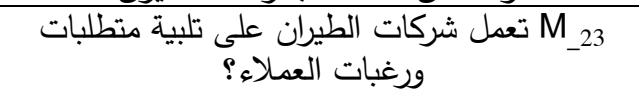 \\
\hline rו & موافق & $V V, T$ & ro,r & $\cdot, 91$ & $\uparrow, \wedge \wedge$ & 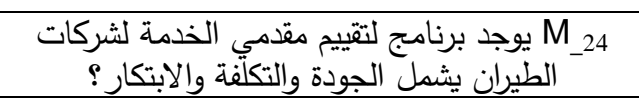 \\
\hline 14 & موافق & $V V, T$ & $r r, \varepsilon$ & $\cdot, 91$ & $\uparrow, \wedge \wedge$ & 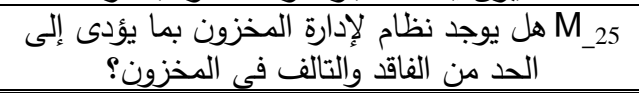 \\
\hline
\end{tabular}

r. r. • المجلد التاسع والأربعون، العدد التاسع، الجزء السابع، سبتمبر

الترقيم الدولي 0826-0 التونون 


$$
\begin{aligned}
& \text { مجلة العلوم البيئية } \\
& \text { معهد الدراسات والبحوث البيئية - جامعة عين شمس لئه } \\
& \text { محمد راشد عثمان وآخرون }
\end{aligned}
$$

\begin{tabular}{|c|c|c|c|c|c|c|}
\hline 㓓: & $\frac{3}{\overline{3}}$ & 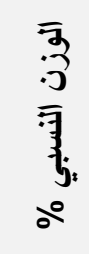 & $\begin{array}{l}\frac{8}{3} \\
\frac{3}{3} \\
\frac{9}{9} \\
\frac{9}{9} \\
2\end{array}$ & 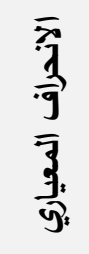 & $\begin{array}{l}\overline{3} \\
\overline{3} \\
\overline{3} \\
\overline{3} \\
\frac{3}{3}\end{array}$ & 高. \\
\hline 10 & موافق & $\checkmark V, \varepsilon$ & $r r, 0$ & $\cdot, 91$ & $r, \wedge \vee$ & 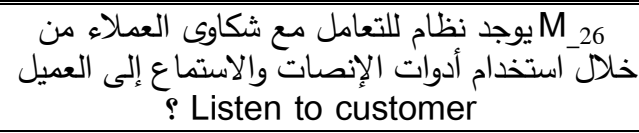 \\
\hline$\wedge$ & موافق & $\vee 9,7$ & $r_{\cdot, T}$ & $\cdot, \wedge r$ & $r, 91$ & ت تتبني الشركة الاهتمام بتلبية حاجة العملاء في \\
\hline & موافق & $V V, r$ & $I V, 0$ & $\cdot, 7 \Lambda$ & r,人т & M مدخل الترشيد(Lean Approach) \\
\hline
\end{tabular}

• جاءت درجة الموافقة "موافق" على مدخل الترشيد، وقد جاءت العناصر مرتبة وفقاً

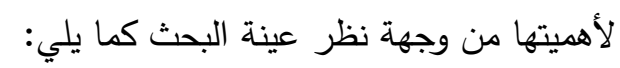
- تعمل شركات الطيران على تلبية متطلبات ورغبات العملاء.

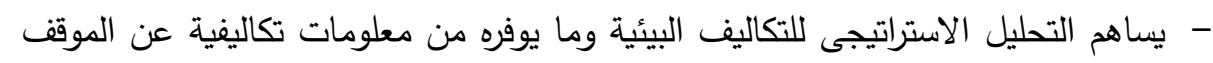

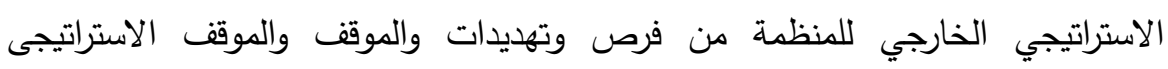
الداخلي من نقاط القوة والضعف فى قدرة المنظمة فى تحقيق مزايا تنافسية.

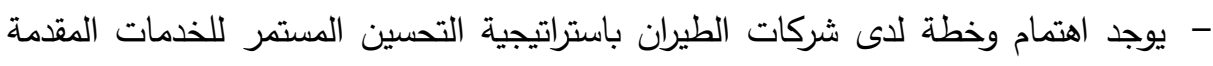
للعملاء.

- يساعد مدخل الترشيد على خفض تكاليف الخدمات المقدمة بشركات الطيران. - - يساعد مدخل الترشيد على خفض حجم التكاليف وتحقيق الريادة التكاليفية بما يدعم المركز

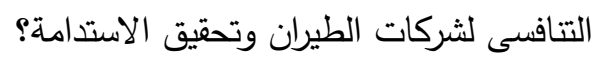
- يعمل مدخل الترشيد على خفض إدارة التكاليف المرتبطة بالخدمات داخل شركات الطيران.

$$
\begin{aligned}
& \text { r. . . المجلد التاسع والأربعون، العدد التاسع، الجزء السابع، سبتمبر }
\end{aligned}
$$

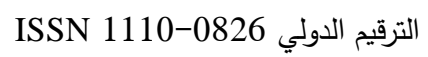




$$
\begin{aligned}
& \text { مجلة العلوم البيئية } \\
& \text { معهد الدراسات والبحوث البيئية - جامعة عين شمس بـ مع } \\
& \text { محمد راشد عثمان وآخرون }
\end{aligned}
$$

- تعمل الشركة على الاستغلال الأمثل للموارد المتاحة لديها بما يؤدى الى ترشيد الاستهلاك ودعم القدرة التتافسية لها. - تتبني الثركة الاهتمام بتلبية حاجة العملاء في رسالتها. - يوجد وعى لدى العاملين بمفهوم وأهمية مدخل الترشيد بشركات الطيران. - تقوم الثركة بالمتابعة والرقابة المستمرة والتحديث للأعمال والعمليات الخدمية. - تعمل الشركة على الحد من الفاقد فى الموارد بما يدعم القدرة التنافسية للشركة.

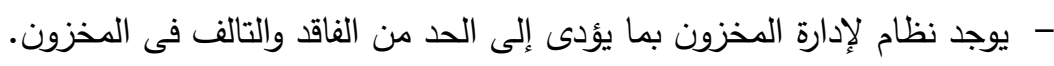
- يوجد برنامج لتقييم مقدمي الخدمة لشركات الطيران يشمل الجودة والتكلفة والابتكار . - يعتبر التخطيط هو المحور الاستراتيجى فى توجيه ورقابة عناصر مخطط تدفق القيمة

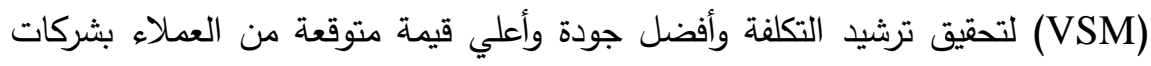

$$
\text { الطيران. }
$$

- يوجد نظام للتعامل مع شكاوى العملاء من خلال استخدام أدوات الإنصات والاستماع إلى لـ العميل Listen to customer - تتم مراجعة إجراءات الحد من كافة أنواع الفاقد. - تقوم شركات الطيران بتحديد الأنشطة التى تضيف القيمة من وجهة نظر العميل ومن ثم الاهتمام بها. - يوجد اهتمام لاى شركات الطيران بسياسة القضاء على الفاقد باستخدام مدخل الترشيد. - تقوم شركات الطيران بإلغاء الأنشطة التى لا تضيف قيمة من وجهة نظر لـات العملاء. - تقوم الشركة بمعالجة الأسباب الجذرية والفرعية المرتبطة بحدوث الأخطاء والفاقد. - يعمل مدخل الترشيد على القضاء على أسباب حدوث المخاطر والأزمات. - تهتم شركات الطيران العربية بمدخل الترشيد.

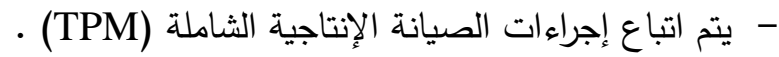

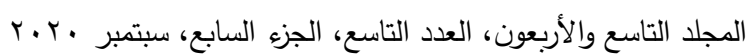

$$
\begin{aligned}
& \text { الترقيم الدولي 0826- ISSN 1110 }
\end{aligned}
$$


- يعمل مدخل الترشيد على معالجة أسباب حدوث المخاطر والأزمات. - تهتم الثركة باستخدام منهجية الستة سيجما فى تحديد الأسباب الفرعية لحدوث الأخطار والمشاكل فى الخدمات المقدمة.

- ينعكس التحليل الاستراتيجى للتكاليف البيئية والعمل على الالتزام بالمتطلبات البيئية بأقل تكلفة مدكنة على الموقف التتافسي للمنشأ. - نظام المحاسبة عن التكاليف والالتزامات البيئية الحالى قاصر على توفير معلومات تحليلية تفصيلية عن التكاليف البيئية على مستوى المنشاة ككل.

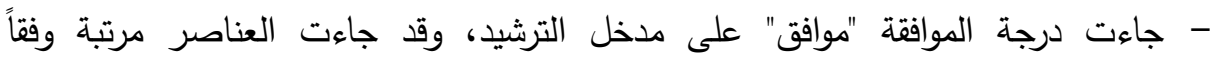
لأهميتها من وجهة نظر عينة البحث كما يلي:

جدول (0): الإحصاء الوصفي مدي أهمية القدرة التنافسية المستدامة

\begin{tabular}{|c|c|c|c|c|c|c|}
\hline 角: & $\frac{3}{\overline{7}}$ & 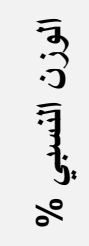 & 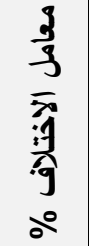 & 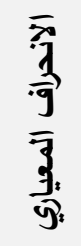 & $\begin{array}{l}\overline{3} \\
\overline{3} \\
\overline{3} \\
\overline{3} \\
3\end{array}$ & $\frac{\overline{3}}{\overline{3}}$ \\
\hline Tr & 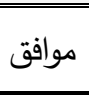 & vo,. & $Y_{0, \Lambda}$ & $\cdot, 9 \mathrm{~V}$ & $r, v_{0}$ & 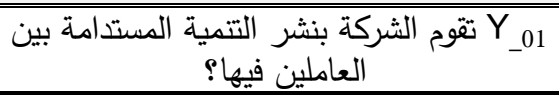 \\
\hline$r \mu$ & موافق & $\vee \vee, 1$ & $r \cdot, T$ & $\cdot, \wedge r$ & $r, 97$ & كسب حصة سوقية أكبر Y_02_A \\
\hline$r \varepsilon$ & موافق & $\vee 9, \cdot$ & Tr,T & $\cdot, 19$ & $r, 90$ & جذب عملاء جدد Y_02_B \\
\hline YT & موافق & $\vee q, \cdot$ & $Y, V$ & $\cdot, \wedge 7$ & $r, 90$ & تحقيق الريادة التكاليفية Y_02_c \\
\hline $1 \pi$ & 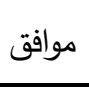 & $\Lambda Y, Y$ & $r \cdot, V$ & $\cdot, \wedge 0$ & $\varepsilon, 1 T$ & 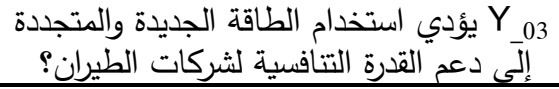 \\
\hline$r$ & موافقِ & $\wedge \uparrow, \wedge$ & $1 \wedge, r$ & $\cdot, \vee \vee 9$ & $\varepsilon, \Gamma \varepsilon$ & 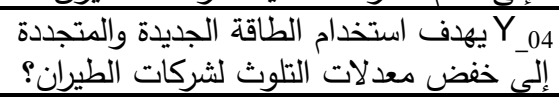 \\
\hline 11 & 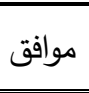 & $\Lambda \Gamma, r$ & $Y r, Y$ & $\cdot, 90$ & $\{, 1\rceil$ & 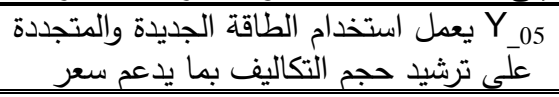 \\
\hline
\end{tabular}


مجلة العلوم البيئية

معهد الدراسات والبحوث البيئية - جامعة عين شمس لبئه

محمد راشد عثمان وآخرون

\begin{tabular}{|c|c|c|c|c|c|c|}
\hline 的 & $\frac{3}{\frac{3}{3}}$ & 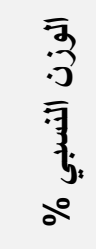 & $\frac{3}{3}$ & $\begin{array}{l}\overline{7} \\
\overline{3} \\
\overline{9} \\
\overline{3} \\
\overline{9} \\
\overline{9}\end{array}$ & $\begin{array}{l}\overline{7} \\
3 \\
\overline{3} \\
\overline{7} \\
3 \\
3 .\end{array}$ & 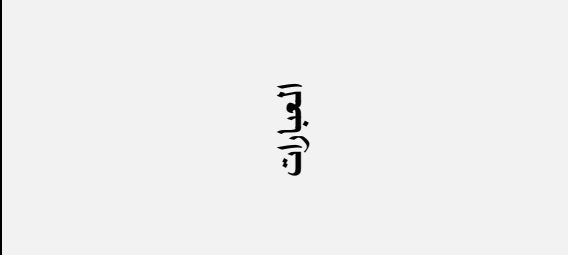 \\
\hline & & & & & & التتافس للخدمات الجوية؟ \\
\hline$\wedge$ & موافقٍ & $\wedge \varepsilon, \varepsilon$ & $r \cdot, r$ & $\cdot, \wedge T$ & $\varepsilon, Y Y$ & 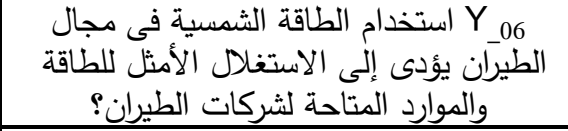 \\
\hline 0 & موافقٍ & $\Lambda T, Y$ & 11,1 & $\cdot, \vee \wedge$ & $\varepsilon, M_{1}$ & 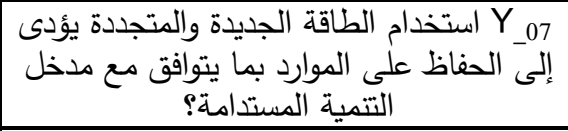 \\
\hline V & موافقٍ & $\wedge \uparrow, 1$ & $19,$. & $\cdot, \wedge r$ & $\varepsilon, \Gamma$. & 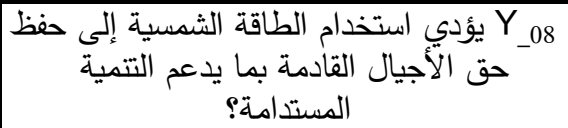 \\
\hline 1 & موافقٍ & $\Lambda \vee, 1$ & $1 V, T$ & $\cdot, V V$ & $\varepsilon, T_{0}$ & 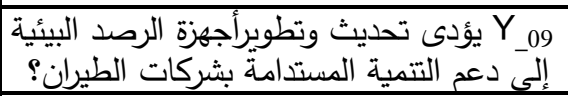 \\
\hline 7 & موافتٍ & $\Lambda \neg, r$ & 11,1 & $\cdot, \vee \wedge$ & $\varepsilon, \Gamma_{1}$ & 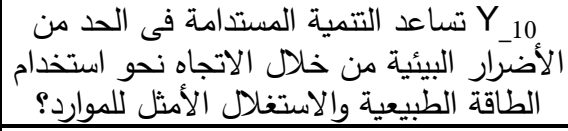 \\
\hline$\varepsilon$ & موافقٍ & $\Lambda 7,0$ & 10,1 & $\cdot, 7 \wedge$ & $\varepsilon, \Gamma$ & 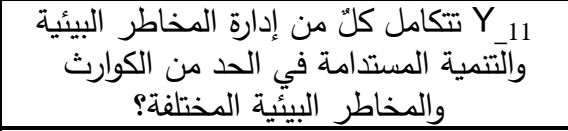 \\
\hline$r$. & موافق & NI, & $r \cdot, l$ & $\cdot, \lambda\rangle$ & $\varepsilon, 0$ & 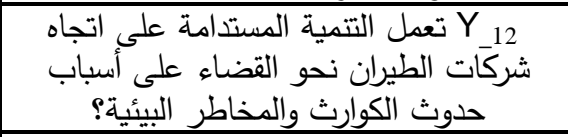 \\
\hline 17 & موافق & $\Lambda Y, r$ & $r \cdot, \varepsilon$ & $\cdot, \wedge \varepsilon$ & $\varepsilon, 11$ & 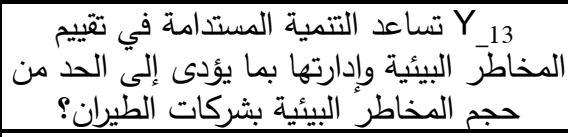 \\
\hline $1 \varepsilon$ & موافق & Ar,r & $r_{\bullet}, \cdot$ & $\cdot, \lambda r$ & $\varepsilon, 1 Y$ & 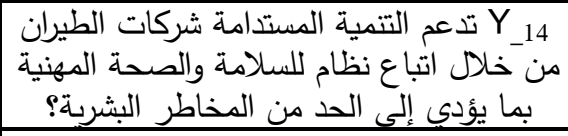 \\
\hline 19 & 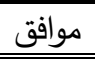 & $\wedge 1,1$ & $19, \varepsilon$ & $\cdot, \vee \vee 9$ & $\varepsilon, .0$ & بـ_15 تدعم استراتيجية التتمية المستدامة \\
\hline
\end{tabular}


مجلة العلوم البيئية

معهد الدراسات والبحوث البيئة - جامعة عين شمس لئية

محمد راشد عثمان وآخرون

\begin{tabular}{|c|c|c|c|c|c|c|}
\hline : 7 & $\frac{3}{\overline{7}}$ & 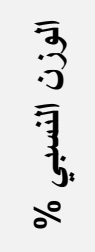 & $\begin{array}{l}\frac{3}{3} \\
\frac{3}{3} \\
\frac{3}{3} \\
\frac{9}{9}\end{array}$ & $\begin{array}{l}\overline{7} \\
\overline{3} \\
\overline{9} \\
\overline{3} \\
3_{2} \\
\overline{9}\end{array}$ & $\begin{array}{l}\overline{7} \\
3 \\
\overline{3} \\
\overline{7} \\
3 \\
3 \\
3\end{array}$ & 亨. \\
\hline & & & & & & 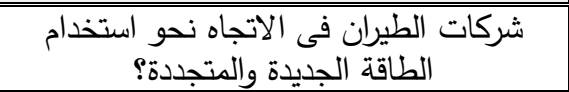 \\
\hline iv & موافق & $\wedge 1,7$ & $1 \wedge, \varepsilon$ & $\cdot, \vee_{0}$ & $\varepsilon, \cdot \Lambda$ & 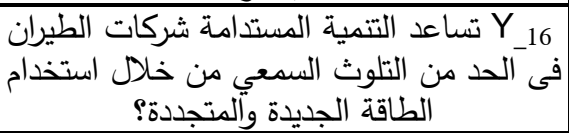 \\
\hline Ir & موافق & $\Lambda \mu, r$ & 19,8 & $\cdot, \wedge)$ & $\{, 17$ & 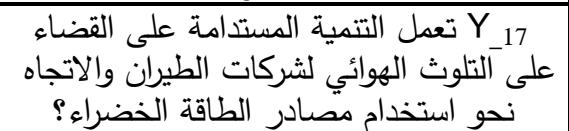 \\
\hline$r$ & موافقً & $\wedge \neg\rceil$, & 11,0 & $\cdot, \wedge$. & $\varepsilon, T r$ & 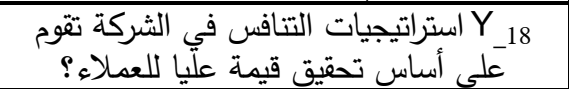 \\
\hline$r q$ & موافق & Vq,r & $r \wedge, \wedge$ & 1,1 . & $r, \wedge r$ & 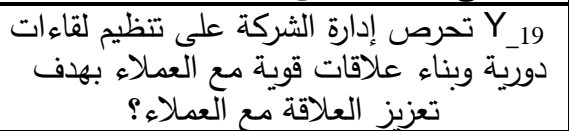 \\
\hline ו & موافق & $v 0,1$ & $r q, r$ & 1,1 . & $r, \vee \uparrow$ & 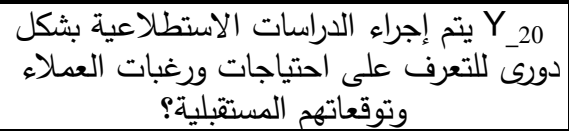 \\
\hline ro & موافق & $\vee \vee, \cdot$ & $r \leq, 1$ & $\cdot, 90$ & r,90 & 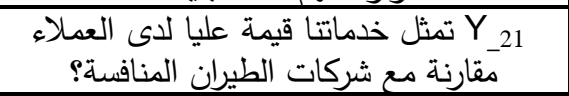 \\
\hline Yr & موافق & $\vee q, \varepsilon$ & $r \varepsilon, q$ & $\cdot, 99$ & r,qV & 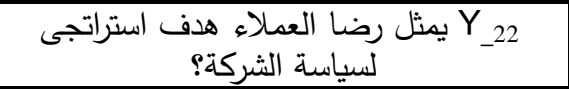 \\
\hline 1. & موافق & r, & $Y, T, T$ & $\cdot, 9 \leq$ & $\{, 17$ & 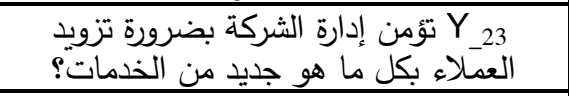 \\
\hline YI & موافق & $\Lambda \cdot, r$ & $r, q, q$ & $\cdot, 9 r$ & $\varepsilon, \cdot 1$ & 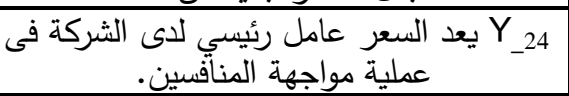 \\
\hline 11 & موافق & 11,0 & $r, Y, O$ & $\cdot, 9 r$ & $\varepsilon, \cdot V$ & 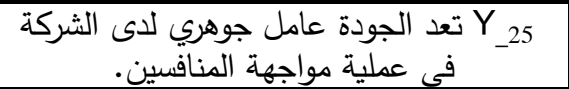 \\
\hline 10 & موافق & $\Lambda r, r$ & $r \cdot, \Sigma$ & $\cdot, \wedge \varepsilon$ & $\varepsilon, \mid Y$ & 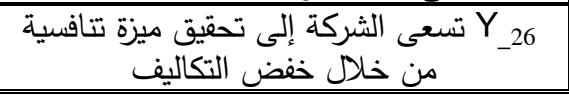 \\
\hline
\end{tabular}

598

r. r. • المجلد التاسع والأربعون، العدد التاسع، الجزء السابع، سبتمبر

الترقيم الدولي 0826-0 الإنون، 
مجلة العلوم البيئية

معهد الدراسات والبحوث البيئية - جامعة عين شمس لئنة

محمد راشد عثمان وآخرون

\begin{tabular}{|c|c|c|c|c|c|c|}
\hline 沗: & $\frac{3}{\overline{3}}$ & 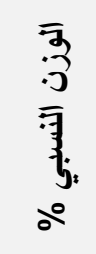 & $\begin{array}{l}\frac{3}{3} \\
\frac{3}{3} \\
\text { ig } \\
\text { go } \\
\text { o0 }\end{array}$ & $\begin{array}{l}\bar{y} \\
\bar{y} \\
\bar{g} \\
\overline{3} \\
\bar{y} \\
\overline{9}\end{array}$ & $\begin{array}{l}\overline{3} \\
\overline{3} \\
\overline{3} \\
\overline{7} \\
3 \\
3\end{array}$ & $\frac{\overline{3}}{9}$ \\
\hline 9 & موافق & $\wedge r, \wedge$ & $r \cdot, V$ & $\cdot, \wedge \vee$ & $\varepsilon, 19$ & 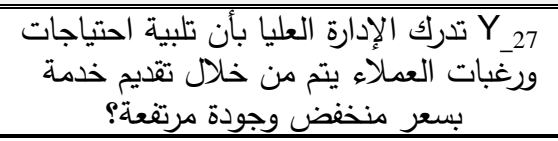 \\
\hline$r \wedge$ & موافق & $\forall \wedge, r$ & $r, r$ & $\cdot, \wedge \vee$ & $r, q)$ & 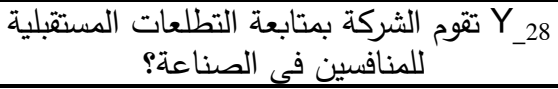 \\
\hline rV & موافق & $\vee \wedge, r$ & $r r, 1$ & $\cdot, 9$. & $r, q)$ & 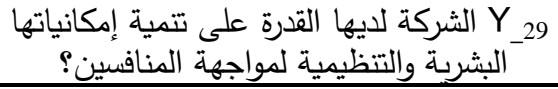 \\
\hline$r$. & موافق & $v_{0, q}$ & $r v, r$ & $1, \cdot \varepsilon$ & $r, \vee q$ & 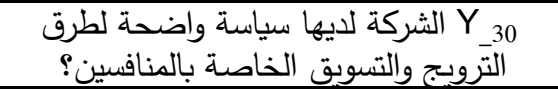 \\
\hline & موافق & $\wedge 1,7$ & 10,9 & $\cdot, 70$ & $\varepsilon, \wedge$ & Pدي أُهمية القدرة التنافسية المستدامة فى الجنق \\
\hline
\end{tabular}

• جاءت درجة الموافقة "موافق" على مدي أهمية القدرة التنافسية المستدامة فى قطاع النقل

الجوى (على المستوى العام)، وعلى مستوى العناصر جاءت درجة الموافقة "موافق جداً" العدئ

على العناصر التالية:

- يؤدى تحديث وتطويرأجهزة الرصد البيئية إلى دعم التتمية المستدامة بشركات الطيران.

- يهدف استخدام الطاقة الجديدة والمتجدة إلى خفض معدلات التلوث لشركات الطيران.

- استراتيجيات التنافس في الثركة تقوم على أساس تحقيق قيمة عليا للعملاء.

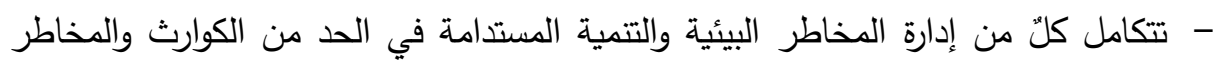

البيئية المختلفة.

- استخدام الطاقة الجديدة والمتجددة يؤدى إلى الحفاظ على الموارد بما يتوافق مع مدخل

التمية المستدامة.

$$
\begin{aligned}
& \text { r.r. . المجلد التاسع والأربعون، العدد التاسع، الجزء السابع، سبتمبر }
\end{aligned}
$$

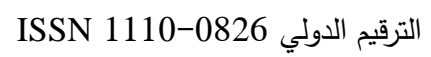


- تساعد التتمية المستدامة فى الحد من الأضرار البيئية من خلال الاتجاه نحو استخدام الطاقة الطبيعية والاستغلال الأمثل للموارد.

- - يؤدي استخدام الطاقة الثمسية إلى حفظ حق الأجيال القادمة بما يدعم التتمية المستدامة. - استخدام الطاقة الثمسية فى مجال الطيران يؤدى إلى الاستغلال الأمثل للطاقة والموارد المتاحة لشركات الطيران. • جاءت درجة الموافقة "موافق" على العناصر التالية: - تدرك الإدارة العليا بأن تلبية احتياجات ورغبات دوات العملاء يتم من خلال تقديم خدمة بسعر منخفض وجودة مرتفعة - تؤمن إدارة الشركة بضرورة تزويد العملاء بكل ما هو جديد من الخدمات.

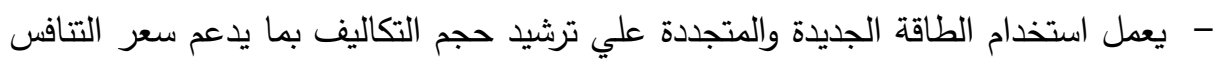
للخدمات الجوية. - تعمل التتمية المستدامة على القضاء على التلوث الهوائي لشركات الطيران والاتجاه نحو استخدام مصادر الطاقة الخضراء. - يؤدي استخدام الطاقة الجديدة والمتجددة إلى دعم القدرة التتافسية لشركات الطيران.

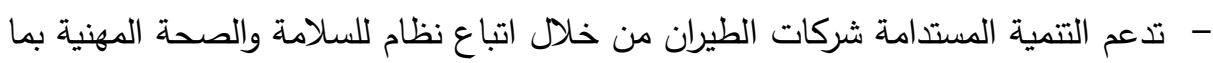
يؤدي إلى الحد من المخاطر البشرية. - تسعى الشركة إلى تحقيق ميزة تتافسية من خلال خفض التهن التكاليف.

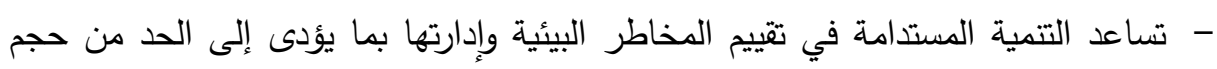
المخاطر البيئية بشركات الطيران. - تساعد التتمية المستدامة شركات الطيران فى الحد من التلوث السمعي من خلال استخدام الطاقة الجديدة والمتجددة. - تعد الجودة عامل جوهري لدى الشركة فى عملية مواجهة المنافسين. 600

$$
\begin{aligned}
& \text { r.r. . المجلد التاسع والأربعون، العدد التاسع، الجزء السابع، سبتمبر }
\end{aligned}
$$

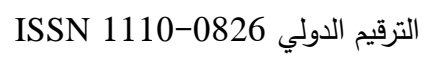


- - تدعم استراتيجية التتمية المستدامة شركات الطيران فى الاتجاه نحو استخدام الطاقة الجديدة والمتجددة. - تعمل التتمية المستدامة على اتجاه شركات الطيران نحو القضاء على أسباب حدوث الكوارث والمخاطر البيئية. - يعد السعر عامل رئيسي لدى الشركة فى عملية مواجهة المنافسين. - يمثل رضا العملاء هدف استراتجى لسياسة الثركة. - - يؤثر التحليل الاستراتيجى للتكاليف البيئية على المركز التتافسى للشركة: كسب حصة سوقية أكبر - جذب عملاء جدد - تحقيق الريادة التكاليفية. - تمثل خدماتتا قيمة عليا لدى العملاء مقارنة مع شركات الطيران المنافسة. - - الثركة لديها القدرة على تتمية إمكانياتها البشرية والتظيمية لمواجهة المنافسين. - تقوم الثركة بمتابعة التطلعات المستقبلية للمنافسين فى الصناعة. - تحرص إدارة الثركة على تظيم لقاءات دورية وبناء علاقات قوية مع العملاء بهدف تعزيز العلاقة مع العملاء.

- - الشركة لديها سياسة واضحة لطرق الترويج والتسويق الخاصة بالمنافسين. نتائج خاصة باختبار فروض البحث: تم قبول الفرض الأول للباحث: توجد علاقة ذات دلالة إحصائية بين تطبيق إدارة المخاطر

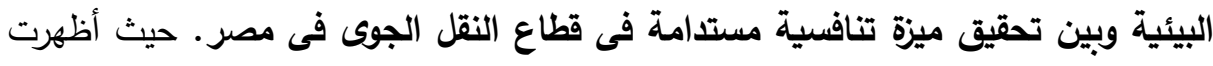

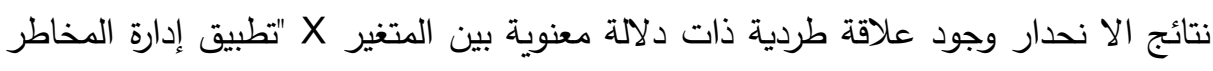

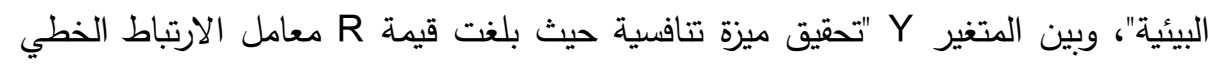

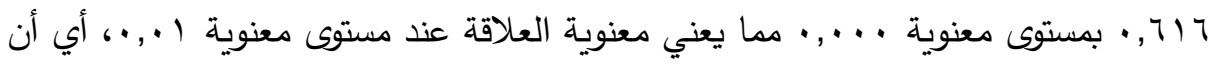
تطبيق إدارة المخاطر البيئية يؤدي إلى تحقيق ميزة تنافسية، لأنه كلما زاد تطبيق إدارة المخاطر البيئية كلما أدى ذلك إلى تحقيق ميزة تنافسية.

$$
\begin{aligned}
& \text { r. . . المجلد التاسع والأربعون، العدد التاسع، الجزء السابع، سبتمبر }
\end{aligned}
$$

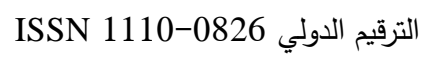


بعد تقدير معالم نموذج الانحدار يمكن صياغة معادلة الانحدار بالثكل التالي: $Y=0.992+0.796 * X+\varepsilon$

حيث: Y تحقيق ميزة تتافسية، X تطبيق إدارة المخاطر البيئية، ع الخطأ العشوائي. وقد ثبتت معنوية النموذج ومعنوية المعلمات المقدرة، وبلغت القدرة التفسيرية للنموذج التهائه \%

تم قبول الفرض الثاني للباحث: توجد علاقة ذات دلالة إحصائية بين استخدام مدخل

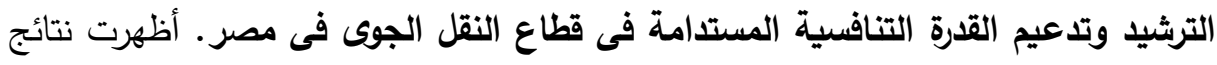
الانحدار وجود علاقة طردية ذات دلالة معنوية بين المتغير M " "استخدام مدخل الترشيد"، وبين

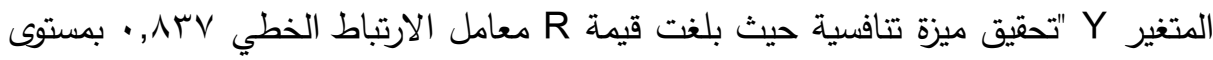
معنوية . .,., مما يعني معنوية العلاقة عند مستوى معنوية ا.., •، أي أن استخدام مدخل

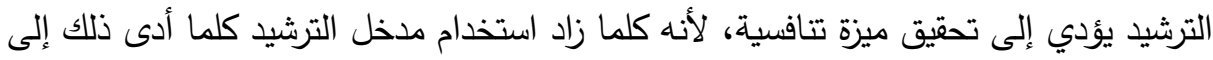
تحقيق ميزة تتافسية. بعد تقدير معالم نموذج الانحدار يمكن صياغة معادلة الانحدار بالثكل التالي: 986+0.803* $\mathrm{M}+\varepsilon . \mathrm{Y}=0$ حيث: Y تحقيق ميزة تتافسية، M استخدام مدخل الترشيد، ع الخطأ العشوائي.

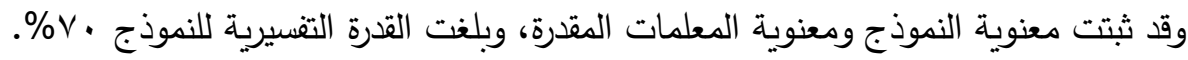
تم إجراء تحليل المسار Path Analysis وأخذات معادلات لامسار الصيخ التالية:

$$
\begin{array}{r}
\mathrm{Y}=0.853+0.206 * \mathrm{X}+0.630 * \mathrm{M} \\
\mathrm{R} \text { square }=0.786 \\
\mathrm{M}=0.220+0.937 * \mathrm{X}
\end{array}
$$

حيث X "ضبط وإدارة المخاطر البيئية"، M "مدخل الترشيد"، Y "القدرة التتافسية المستدامة. 


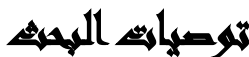

في ضوء النتائج التي توصل إليها الباحثون سابقًا، يمكن إبراز أهم التوصيات فيما يلي: - توجيه مزيد من الاهتمام بمجال البحوث والتطوير المستمر حول المناهج العلمية الحديثة وكيفية تطبيقها داخل المؤسسات والثركات المختلفة، من أجل تعظيم العائد على الأصول المادية والحد من المخاطر البيئية ودعم القدرة التتافسية.

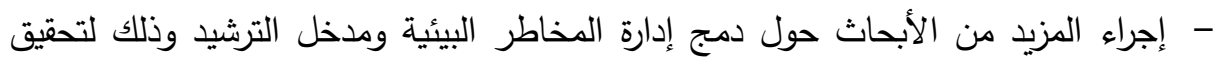
أقصى استفادة ممكنة والجمع بين مزايا كل منهجية. - الاستفادة من مدخل الترشيد في رفع كفاءة العنصر البشري وتتمية مهاراته وقدراته من من مناهي خلال البرامج التدريبية اللازمة وتقديم سبل الدعم والتحفيز المادي والمعنوي، توفير بيئة عمل مناسبة، مشاركته في اتخاذ القرارات الإدارية. - القضاء على أسباب ومعوقات تتفيذ ادارة المخاطر البيئية من خلال مواجهة الفساد الإداري داخل المنظمات والأجهزة الإدارية المختلفة، الحد من أسباب حدوث التيدي التلوث البيئى.

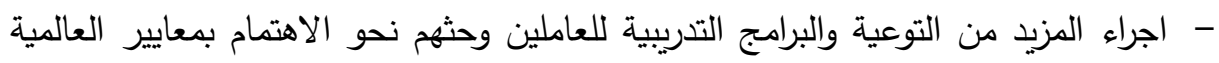

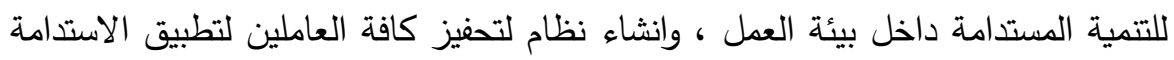
بمفهومها الواسع الذى يشمل كافة القطاعات والإدارات داخل المنظمات والمؤسسات المختلفة ، بما يؤدى الى زيادة مستوى كفاءة العنصر البشرى والاستغلال الأمثل للموارد وخفض معدلات التلوث وبالتالى خفض التكاليف. - ادخال مفاهيم ادارة المخاطر البيئية ضمن المناهج والخطط التدرببية لشركات الطيران العربية. - ادخال عناصر مدخل الترشيد وآلياتة ضمن معايير تقييم أداء العاملين بشركات الطيران العربية.

$$
\begin{aligned}
& \text { r. . . المجلد التاسع والأربعون، العدد التاسع، الجزء السابع، سبتمبر }
\end{aligned}
$$

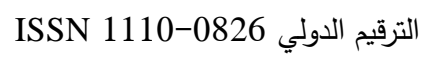




$$
\begin{aligned}
& \text { مجلة العلوم البيئية } \\
& \text { معهد الدراسات والبحوث البيئية - جامعة عين شمس لعس آخس }
\end{aligned}
$$

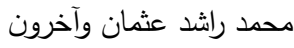

- دعم الإدارة العليا لتنفيذ وتطبيق آليات ادارة المخاطر البيئية فى كافة الإدارات داخل شركات الطيران العربية ومنظومة النقل الجوى.

- نشر ثقافة إدارة المخاطر البيئية وإبراز أهميتها على اداء شركات الطيران العربية.

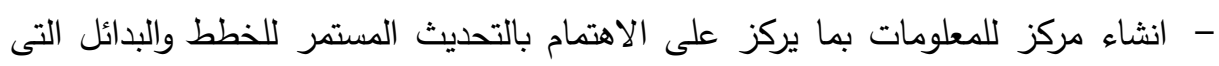
يمكن من خلالها ادارة المخاطر البيئية.

- العمل على زيادة القيمة لدى العملاء ومن ثم استدامة القدرة التتافسية لشركات الطيران العربية.

- تدعيم استراتيجية التتمية المستدامة شركات الطيران فى الاتجاه نحو استخدام الطاقة الجديدة والمتجددة.

- تساعد التنمية المستدامة في تقييم المخاطر البيئية وإدارتها بما يؤدى إلى الحد من حجم المخاطر البيئية بشركات الطيران. - تفعيل دور التتمية المستدامة على القضاء على التلوث الهوائي لشركات الطيران والاتجاه نحو استخدام مصادر الطاقة الخضراء. - استخدام الطاقة الجديدة والمتجددة فى دعم القدرة التتافسية لشركات الطيران. - تدعيم التتمية المستدامة لدى شركات الطيران من خلا اتباع نظام للسلامة والصحة المهنية بما يؤدي إلى الحد من المخاطر البشرية.

\section{caloull}

إبراهيم عثمان شاهين (ع ( ب ب): كتاب المراجعة: دراسات معاصرة وحالات عملية. مؤسسة

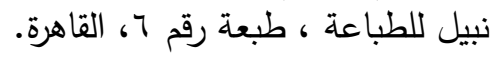

أحمد فرغلي محمد حسن (99V (1)): دراسات مستقبلية في المحاسبة البيئية والموارد الطبيعية (الإطار العام). القاهرة، المكتبة الأكاديمية.

604

$$
\begin{aligned}
& \text { r. . . المجلد التاسع والأربعون، العدد التاسع، الجزء السابع، سبتمبر }
\end{aligned}
$$

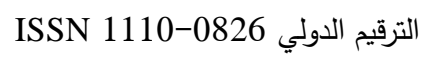




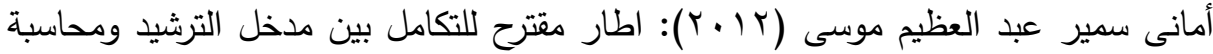
استهلاك الموارد بغرض دعم المركز التتافسى للوحدات الاقتصادية - دراسة الماتية

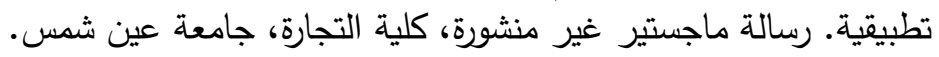

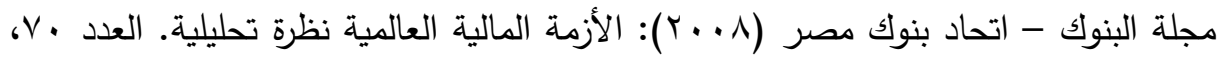

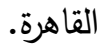

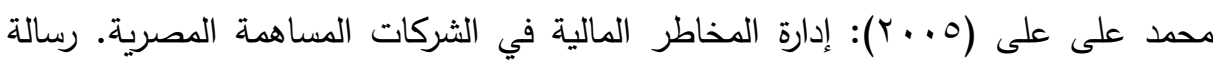
دكتوراه غير منشورة، كلية التجارة، جامعة القاهرة.

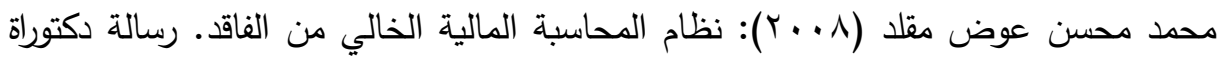
غير منشورة ، كلية التجارة, جامعة طنطا.

محمد مؤنس محب الدين (1990): البيئة في القانون الجنائي - دراسة مقارنة. دار النهضة

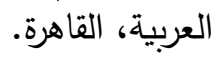

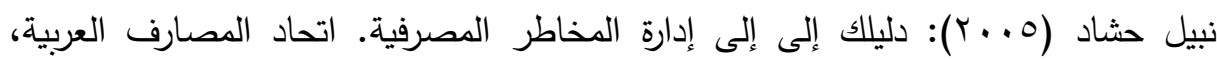

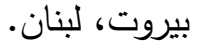

نهال احمد الجندي (1) (1): إعادة هندسة نظم المحاسبة الإدارية لتتوافق مع مدخل محاسبة

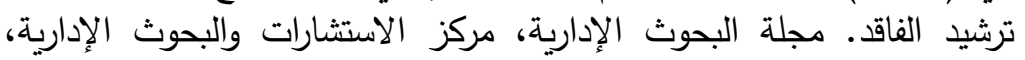
المجلد 9 ج، العدد ال، أكاديمية السادات للعلوم الإدارية.

Ana- Maria (2013): The Economic Dimension of Environmental Risk management in knowledge- Based society. PHD thesis, Dimitrie cantemir University. bucharest.

Anna Dorota Rymarzewska (2016): Re thinking the applicability of lean philosophy a conceptual and empirical analyin", vaasam ylipito, university of vaasa.

Anna Misiura (2015): Enterprise Risk Management In The Airline Industry - Risk Management Structures And Practices. PHD Thesis، Brunel University, London، PP.2-127.

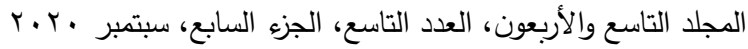

$$
\begin{aligned}
& \text { الترقيم الدولي 0826- ISSN 1110 }
\end{aligned}
$$




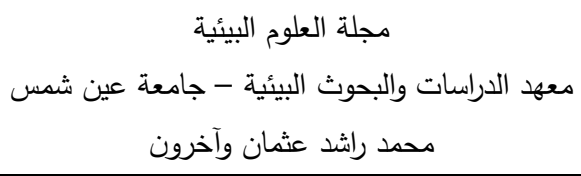

Asieh Fathali (2016): Examining the impact of competitive strategies on comparaten innovation i An Empirical study in Automobile industry. International Journal of Asian social science, vol 6, Issue 2.

Asmi Ali (2016): Exploring lean strategy fo service quality improvements in UK baled airline. PHD thesis, Bunge Buinen school, London

Basel committee on banking supervision (1996): Part B of "The Amendment to the capital accord to incorporate market risk".

Bozdogan, K. (2010): Evolution of the Lean Enterprise System; Acritical Synthesis and Agenda for the future. July. Available at: http://ssrn.com.

Carlbrog, per, kindstrom, Daniel \& Kowalkowski, Christian (2013): A Lean approach to service productivity improvements: Synergy or oxymoron 2. Managing service Quality, (23),4. PP. 291-304.

Chianu Hamony Dibia (2017): Lean Manufacturing and employee working condition in olganijation opeating in nigeia : the manage' and sapevisos' pespective. PhD Thesis, University of portjmoath.

David Rios Insua (2013): Risk Analysis and safety decision-making in commercial air transport operations. PHD thesis, rey juan carlos university

Davis, Charles E. and Davis, Elizabeth (2012): Accounting. John Wiley And Sons, Inc.,USA.

Drivnsek (L) 2 (1990): Preserver Lenvironnment. Cujas Paris.

606

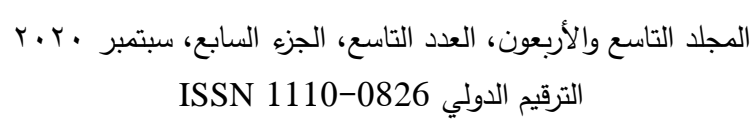




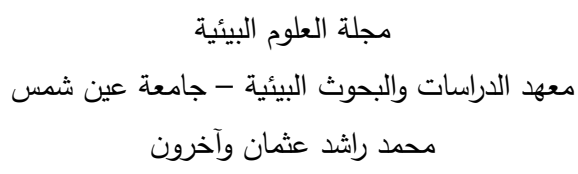

Fawag Abdullag (2003): Lean Manufacturing tools and technique in the process industry wilg A foul on steel. PHD thesis, Universality of pittdbugh.

Grasso L. P. (2005): Are ABC and RCA Accounting Systems Compatible With Lean Management. Management Accounting Quarterly, Vol. 7, Issue 1,.

Hsun. I huong (2012): An Empirical analysis of the Ba strategic Mandgement of competitive advantage : A case study of Higher technical and Vocational Education in Taiwan. PHD Thesis, victoria university.

Industry - risk management structures and practices. Innovation, Management and Technology, Vol.2, No.2.

Magee, David (2007): How Toyota Became. (New York: Portfolio, 17)

Nur Aishah Binti Awi (2016): The Effect of Lean Kaizen Application on student's satisfaction Malaysian Highez. Education sector. PhD thesis Be caventti, University.

Omar Rabeed Mahdig (2013): The role of strategic leadership - in Building sustainable Competitive Advantage in the Academic Environment. International Conference on innovation, Malaysia

Palanivel Subramaniyam (2011): An Innovative lean six sigma PHD Thesis, Brunel University, London.

Sean Murphy (2011): The Status of Lean Implementation within South African Aircraft Maintenance Organization", Master's thesis, Faculty of Engineering, University of Witwatersrand, Johannesburg.

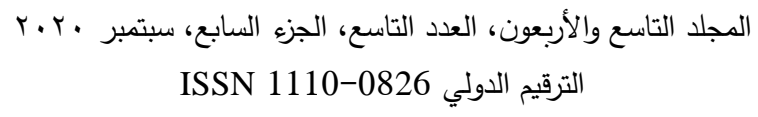




$$
\begin{aligned}
& \text { مجلة العلوم البيئية } \\
& \text { معهد الدراسات والبحوث البيئية - جامعة عين شمس البرس } \\
& \text { محمد راشد عثمان وآخرون }
\end{aligned}
$$

Tatyana Chernova (2014): Risk management Application for the IATA E-Freight initiative in air cargo industry. Master thesis, Tampere University of Technology.

Tyler Spence (2016): An evaluation noise reduction strategies at large commercial airports in the united states : Apolicy anslysis and framework classification. PHD Thesis, Purdue University.

William H. Beaver \& George Parke (1995): Risk Management: Problems \& Solution. Stanford University: Mc Graw- Hill, Inc.

http://ww.routledge.com.

https// :www.un.org.

https://ar.m.wikipedia.org

https://en.wikipedia.org/wiki/biometric-device : 2019

http://www.tandfonline.com.loi/tpmr.

608

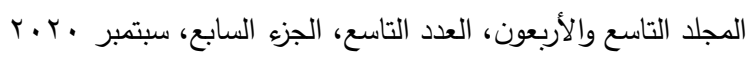

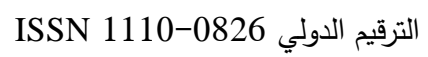




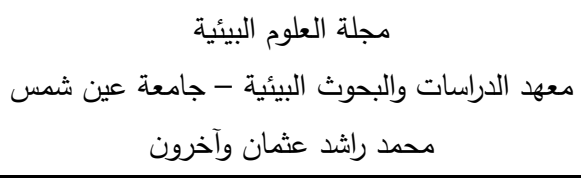

\title{
A SUGGESTED FRAMEWORK FOR ENVIRONMENTAL RISKS MANAGEMENT USING LEAN APPROACH TO ENHANCE THE SUSTAINABLE COMPETITIVE CAPABILITY FOR
} EGYPTIAN AIR TRANSPORTATION SECTOR

\author{
Mohammad R. Othman (1); Gamal S. Khatab ${ }^{(2)}$ \\ Mohammad A. Nada $^{(3)}$
}

1) Egypt Air 2) Faculty of Commerce 3) Institute of Management and Cooperative Studies

\begin{abstract}
A human being is considered the vital factor in making environmental changes and developments; since his existence, he is dealing with the environment's components. The more increasing of days, the more controlling and authorizing upon the environment, particularly, after the scientific and technological advance have provided him more chance to make change in the environment. The main objective of this paper is to set up a proposed framework for controlling and managing environmental risks using the Lean Approach or the Lean Thinking which compromise between stipulations and theoretical dimensions and practical practices, for the purpose of achieving competitive sustainable ability and their reflection on supporting the competitive sustainable position of the air transport sector and also the airline companies. The researchers count on the inductive method through collecting and analyzing studies involved in the research field; using also the deductive method through counting on logical causal thinking at implementing the field study to presenting a

$$
\begin{aligned}
& \text { r.r. المجلد التاسع والأربعون، العدد التاسع، الجزء السابع، سبتمبر } \\
& \text { الترقيم الدولي 0826- ISSN 1110 }
\end{aligned}
$$




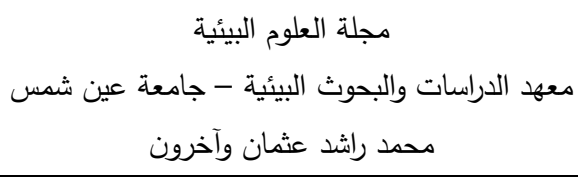

proposed framework for managing and controlling environmental risks. The researcher also uses the Lean Approach for supporting the competitive sustainability of the air transport sector in the Arab Republic of Egypt. A final list of the field study data collection has been designed. In light of the results obtained from the initial exploratory study and three research axes, which are: The first axis: managing and controlling environmental risks in the air transport sector, and this axis is measured by a number ( 26 closed questions and one open question); the second axis: an introduction to rationalization in the air transport sector in the Arab Republic of Egypt, and this axis is measured by ( 27 closed questions and one open question); the third axis: the importance of sustainable competitiveness in the air transport sector, and this axis is measured by (30 closed questions and an open question), and the fourth axis: the link between managing and controlling environmental risks by using the lean approach to support the sustainable competitiveness of the air transport sector and this axis is measured by (11 closed questions). The researcher has used for designing the list, a mixed method that combines closed and open questions. Most of them are closed due to their ease of coding and analysis, in addition to adding an open question in the study axes, to explore the sample's information that has not been included in the closed question. It is recognized that the civil aviation sector plays a fundamental and pivotal role in the lives of peoples or countries (modern era). In terms of globalization, the importance of air transport is evident and reflected in the economic and social development of countries as well as the revitalization of tourism and international trade. Egypt Air is the main representative of the Egyptian air transport sector. It plays a prominent role in the Egyptian economy. For Egypt, the field of civil aviation (air transport) has a major role in advancing economic development, as tourism is considered as one of the most important sources of the national income and the increased foreign exchange.

610

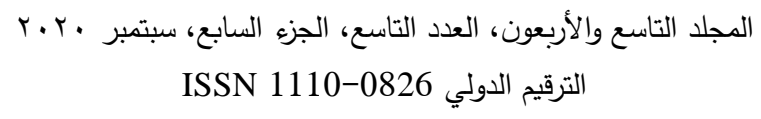




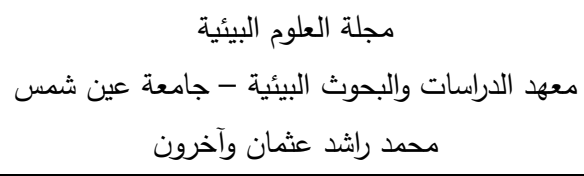

The study concludes with presenting a proposed framework for managing environmental risks by using the rationalization approach to support the sustainable competitiveness of the air transport sector in the Arab Republic of Egypt.

The study recommends the necessity consider the approach of rationalization and benefit from its mechanisms in environmental risk management, for the purpose of strengthening sustainable competitiveness and interest in conducting more studies, research and continuous development in modernizing management systems, procedures and various works, relying as well, on new and renewable energy instead of using fossil energy.

Keywords: Environmental Risk Management, Lean Approach, Competitive Advantages, Sustainable Development, Sustainability, Air transport.

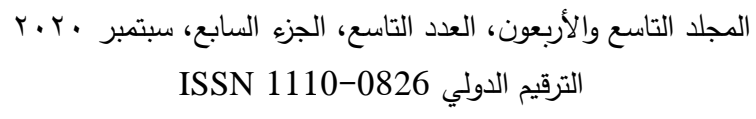

